\title{
Design and Experimental Investigation of a Novel Skip Cycle Mechanism
}

Fırat Mehmet Günkan ( $\nabla$ fmgunkan@itu.edu.tr )

Istanbul Teknik Universitesi https://orcid.org/0000-0003-2754-4852

Cemal Baykara

Istanbul Teknik Universitesi

Osman Akın Kutlar

Istanbul Teknik Universitesi

\section{Original Article}

Keywords: valve control, skip cycle mechanism, skipcycle strategy, cam design, cycle optimization

Posted Date: May 14th, 2020

DOl: https://doi.org/10.21203/rs.3.rs-24146/v1

License: (1) This work is licensed under a Creative Commons Attribution 4.0 International License.

Read Full License 


\title{
Design and Experimental Investigation of a Novel Skip Cycle Mechanism
}

\author{
Firat Mehmet Gunkan*1, Cemal Baykara ${ }^{1}$, and Osman Akin Kutlar ${ }^{1}$ \\ (fmgunkan@itu.edu.tr) (baykaracem@itu.edu.tr) (kutlar@itu.edu.tr) \\ ${ }^{1}$ Faculty of Mechanical Engineering, Istanbul Technical University, \\ Gumussuyu 34437, Istanbul, Turkey \\ ${ }^{*}$ Corresponding Author
}

\begin{abstract}
The main problem in near future is to increase the efficiency of internal combustion engines, which is the most important cause of air pollution in cities and the reduction of exhaust emissions from these engines. When operating conditions are examined in passenger cars, which are the main users of internal combustion engines, it has been seen that high fuel consumption occurs in the partial load area. A new working method for internal combustion engines, skip cycle strategy, which were revealed by Kutlar in 1999 has similarities with the cylinder deactivation systems, but it also has advantages especially in the application to single cylinder engines. The skip cycle strategy is a method of reducing the power taken by the engine, in other words, reducing the pumping losses in the partial load area. In this work, the control process has been provided according to cycle conditions and depending on skip cycle system needs, besides the mechanical valve control. The created mechanism consists of two groups: lock system and control system. In this study, the kinematic analysis of the engine has been carried out and the loads acting on the system have been determined. Finally, mechanism has been manufactured and experiments have been carried out at different speeds according to the NS (Normal cycle-Skip cycle) method, which is one of the several skip cycle strategies.
\end{abstract}

Keywords: valve control, skip cycle mechanism, skipcycle strategy, cam design, cycle optimization

\section{Introduction}

The daily fuel consumption of spark ignition engines is approximately one third of world fuel production. It is thought that petroleum reserves will not need to demand in the near future. Consumption of oil reserves beside exhaust emissions and air pollution which increase because of the increasing number of passenger cars, reveals the importance of fuel consumption at internal combustion engines. Nowadays, the effective efficiency of a internal combustion engine is about $35-40 \%$, in the partial load area is approximately $10-15 \%$. The most important reason of this is the pumping losses. Today, different methods are applied to increase the efficiency in the partial load area. The most important of these methods are variable valve timing [1], variable compression ratio [2], supercharging, variable stroke volume.

A new working method for internal combustion engines, skip cycle strategy, which were revealed by Kutlar in 1999 has similarities with the cylinder deactivation systems, but it also has advantages especially in the application to single cylinder engines. As well as the multi cylinder systems the skip cycle strategy is a method of reducing the power taken by the engine, in other words, reducing the pumping losses in the partial load area. However, instead of disabling a certain number of cylinders, such as in the variable stroke volume method, each cylinder is intended to inactivate and activate each other in successive cycles [3]. With this method, fuel 
and air intake are blocked in some of the successive cycles when the engine load is reduced, it should be increase the fill intake to achieve the same power. Thus, an increase in effective efficiency is expected. But the most important problem is that fuel blocking will not reduce the pumping losses in the cycle where the work is not produced. Therefore, the valves must be completely closed in order to prevent negative work in other words to prevent the air intake into the cylinder during intake time.

Several mechanisms have been designed or are currently in use to control the valves in technical literature. Most of them have advantages and disadvantages according to working conditions. The BMW Valvetronic system developed by BMW [4][5], unlike normal system, consists of an extra arm and follower. In this system, the arm position provides the desired valve clearance by controlling the rocker arm aperture. The control engine has been connected to the worm wheel and the worm gear depending on the arm. So that the position of the arm and thus the valve control is provided. In the Valvelift system developed by Audi [6], the camshaft operates according to the principle of position adjustment by entering the electronically controlled pins into the helical channels on the system. Thus, the valve is controlled by two different cam profiles according to the condition of the engine. This system is more complicated than other mechanisms. Variocam Plus system controls both variable valve timing and variable valve clearance. Control of this system is done hydraulically [7]. In Nagaya's work [8], an inclined cam profile controlled by a worm gear connected to the electric motor controls the valve with both variable timing and variable valve opening operations performed at the same time. In Eaton company mechanism, two-stage valve opening has been controlled by controlling nested two cylindrical bodies with pins, externally [9]. The cylindrical spring between the two bodies provides the return motion. Another mechanism replaced in rocker arm was patented by Morita [10]. While this mechanism is also intended to be used in cylinder deactivation systems, it has been determined that there is a gap of $0.12 \mathrm{~mm}$ which leads to fill leakage. In Basshuysen's study, a hydraulically controlled mechanism has been considered to be used for valve deactivation process by placing it between the cam profile and the valve [11]. This mechanism body has been specially designed to direct the fluid. This design has sealing problems relating to fluid leakage. In this work, the control process has been provided according to cycle conditions and depending on skip cycle system needs, besides the mechanical valve control. The created mechanism consists of two groups: lock system and control system. In this study, the kinematic analysis of the engine has been carried out and the loads acting on the system have been determined. Finally, mechanism has been manufactured and experiments have been carried out at different speeds according to the NS (Normal cycle-Skip cycle) method, which is one of the skip cycle strategies.

\section{Methodology}

\subsection{The Design of Skip Cycle Mechanism}

In the skip cycle system developed by Kutlar, the pumping losses will not be reduced in the cycle where the work will not be produced (or workless cycle) by cutting the fuel only. Therefore, the valves must be completely closed in order to prevent air entering the cylinder during intake time. The mechanism consists of two main parts; the locking mechanism and the control mechanism. Fig.1.

The locking mechanism has been located just above the valve, so that it can be used in singlecylinder or multi-cylinder systems without any intervention to the cam and rocker arm mechanism. In addition, the filler leakage on the valve are controlled due to the connection of the lock mechanism with the physical connection. It also allows the use of different cycle strategies by controlling the lock mechanism with the help of pins.

The control of the locking mechanism is carried out with control cams which are operated in 
synchronism with the crankshaft and mechanically controlled. The mechanism is also designed to be able to respond to different strategies because there are more than one strategy in the skip cycle approach. The profiles of the control cams have been calculated according to the angular analysis of the crankshaft and the targeted strategy.

In addition, the skip cycle system not only controls the intake valves but also the exhaust valves.

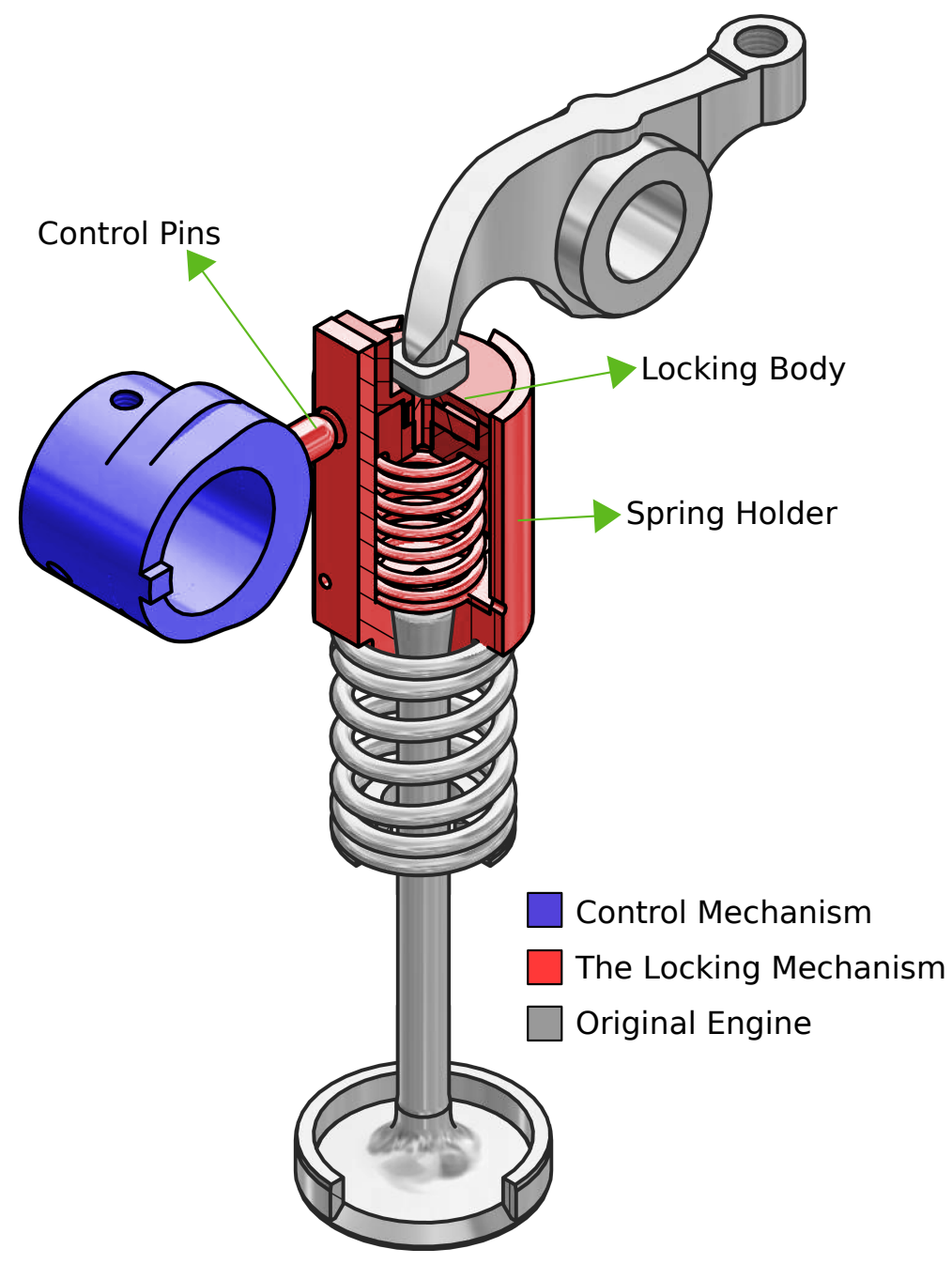

Figure 1: Skip Cycle Mechanism

\subsection{Working Principle of Skip Cycle Strategy}

Skip cycle mechanism prevents to open the valves so that no work is produced in the stage after 4 cycles of power generation. There are two positions in the mechanism to prevent the opening of the valves: Position in which the valves are closed (locking mechanism disabled, skipped cycle) and valve open position (lock mechanism active, normal cycle).

\subsubsection{Disabled Mode of Poppet Valve}

The pusher pins, which get the movement from the controller cam, fixes the main spring holder to the cylinder head. Therefore, the lock body will be released into the main spring holder. At the same time, the camshaft transmits the motion from the system with the help of pushrod and the rocker moves downwards. The free lock body moves vertically in the spring holder. The rocker return motion is provided by an additional return spring in the locking system. The valve movement will be canceled in the lock position cycle, because the main spring holder to 
which the valve is connected is fixed. (Fig. 2a)

\subsubsection{Enabled Mode of Poppet Valve}

The pin group receiving the return motion from the return cam is in the free position in the lock body. For this reason, the main spring holder and the cylinder head are separated from each other and locked with 3 points by the lock body. At the same time, the camshaft transmits the motion from the system with the help of pushrod and the rocker moves downwards. The position of the pusher pin group connects the lock body with the main spring holder, so that the main spring is moved downward by the rocker. The valve will move in the free position since the spring holder is attached to it. Thus, the cycle will be completed normally. (Fig. 2b).

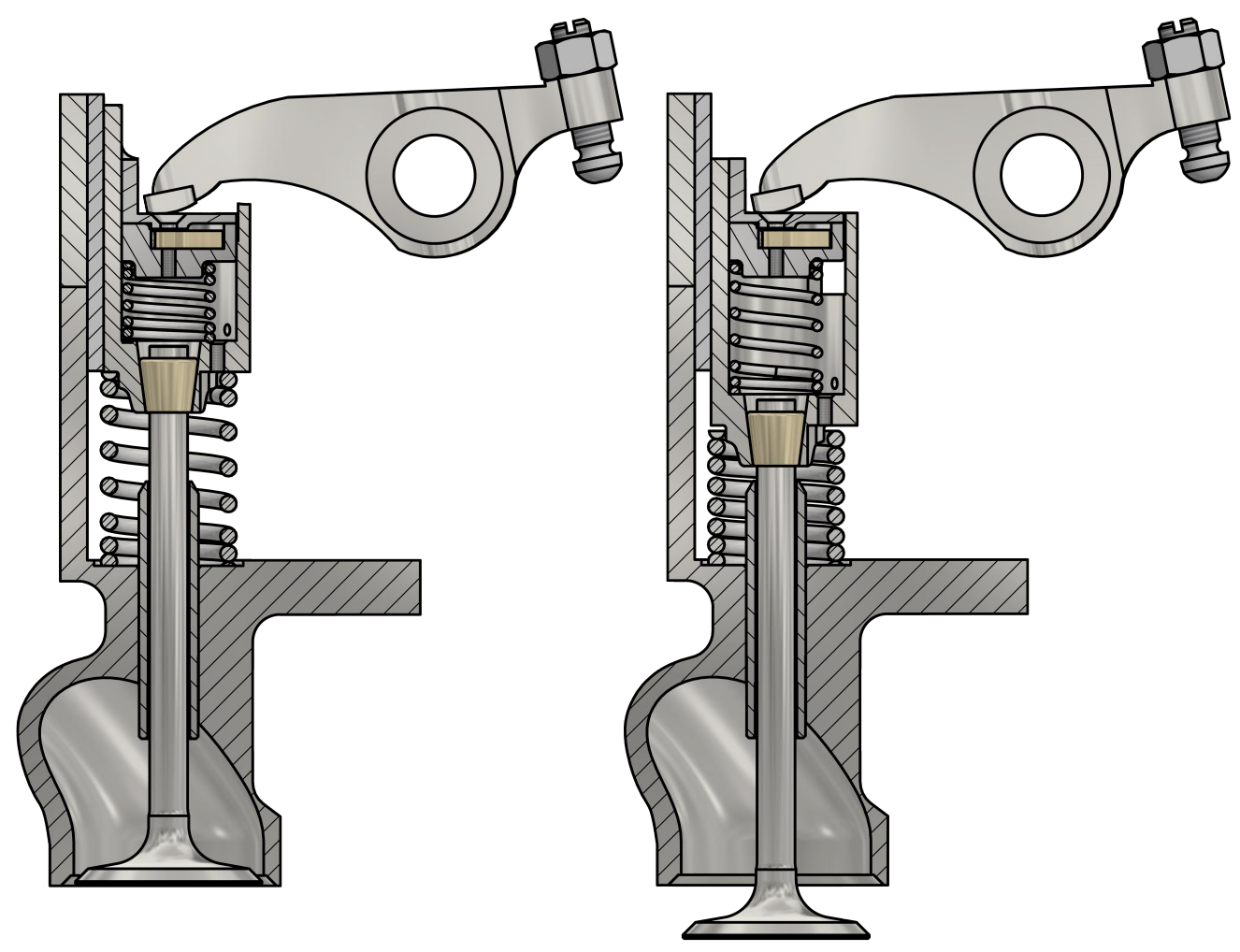

Figure 2: a) Disabled mode (on left), b) Enabled mode (on right)

\subsection{The Locking Mechanism}

The control of the mechanism has been provided by pins. When the positions of the pins are examined, the rocker in the first position in Figure 3a will push the lock mechanism. During this time, the valve will not open, and the cycle will be skipped. The other pins hold the main spring holder, which is connected to the valve, by the shape connection, so that filler leaks will be prevented. In Figure 3b, the lock body has been locked with the main spring holder pins and the valves are opened, so normal cycling takes place. 

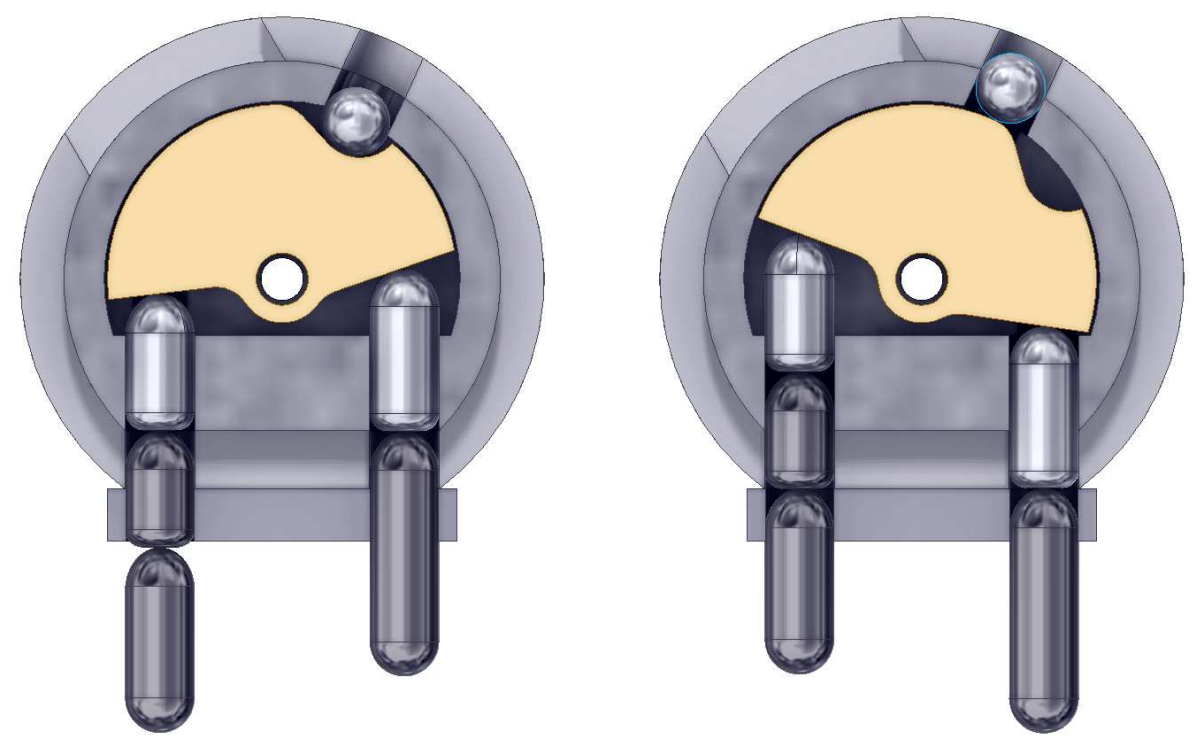

Figure 3: a) Locking position (Skip Cycle), b) Unlocking position (Normal Cycle)

Spring holder body: It plays an important role in adjusting the position of pins and locking position. The positions and diameters of the control pins have been used to determine the dimensions of the planar region to prevent rotation of the main spring retainer about its axis. The lower part of the spring holder is closed. The oil must not accumulate during operation and the support parts must be lubricated. For this reason 6 oil drain holes with a diameter of $2 \mathrm{~mm}$ have been opened in equal intervals around the main spring holder.

Control Pins: They control the system by receiving movement from the control cam group. There are 5 pins in the system. When the positions of the pins are examined, the rocker in the first position in Figure 3a will push the lock mechanism. During this time, the valve will not open, and the cycle will be skip. The other pins hold by the shape connection the main spring holder which is connected to the valve, so that filler leaks will be prevented. In Figure $3 \mathrm{~b}$, the lock body has been locked with the main spring holder pins and the valves are opened, so normal cycling takes place.

Pushing Cam: It controls the forward and backward control of the pins and the locking of the sphere. It is located in the lock body.

Locking Body: It forms the body of all the elements used in the locking operation and allows the pins to bear when moving.

\subsection{Control Mechanism}

Specially designed cam profiles for pins position control have been used. The engine used in the experimental setup is a 4 -stroke engine. Therefore, there is a ratio $1 / 4$ between the control cam and the crankshaft. The control cam profiles considering this conversion ratio have been designed according to the angle values given in Table 1 for the NS strategy. The NS and NSS control cam diagrams are given in the Figure 4

\begin{tabular}{cc}
\hline Control Cam & Reverse Cam \\
\hline Rise 0-55 & Dwell 0-125 \\
\hline Dwell1 55-180 & Dwell1 55-180 \\
\hline Fall 180-235 & Fall 180-235 \\
\hline Dwell2 235-360 & Dwell2 235-360 \\
\hline
\end{tabular}

Table 1: Control Cam Parameters for NS Strategy 

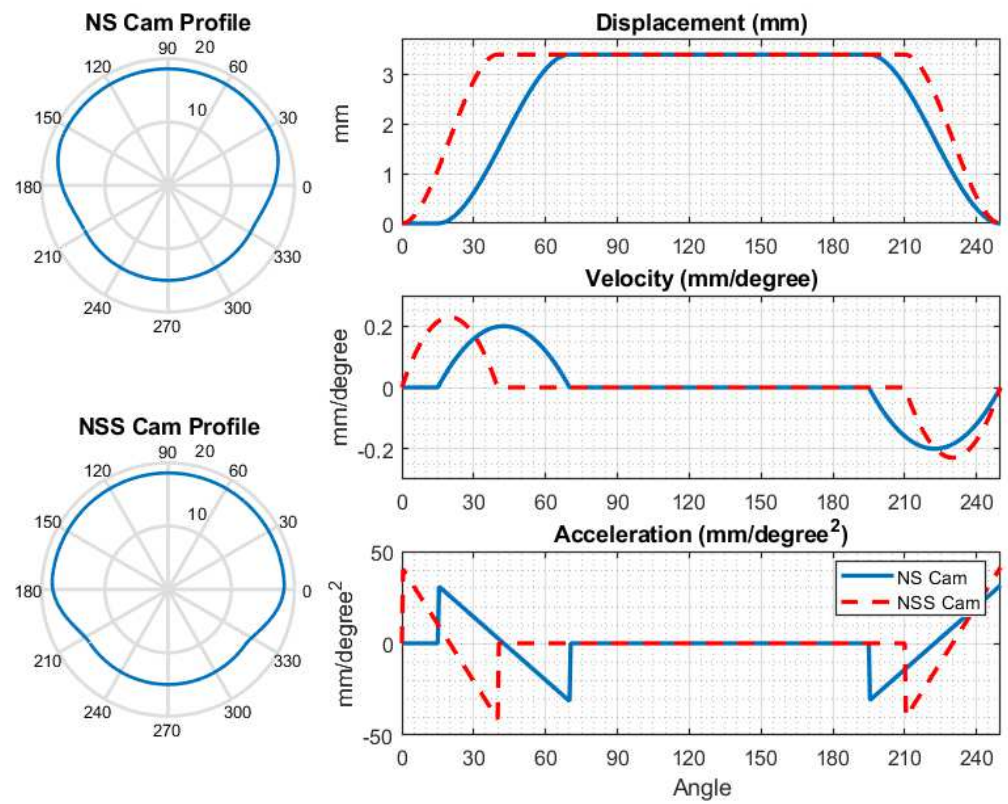

Figure 4: NS and NSS Strategy Control Cam Profiles

A 3-4-5 polydin cam equation has been chosen for the control cam motion equation. There are two symmetrical cams in the control cam group, which determine the position of the control pins. The first one is named as the control pin and determines the position of the pins. The other is called returning cam and brings the pins to the initial position Fig. 1. The control camshaft and the crankshaft must also be synchronized. Fig. 5. To this end, movement and power transmission have been provided with a timing belt.

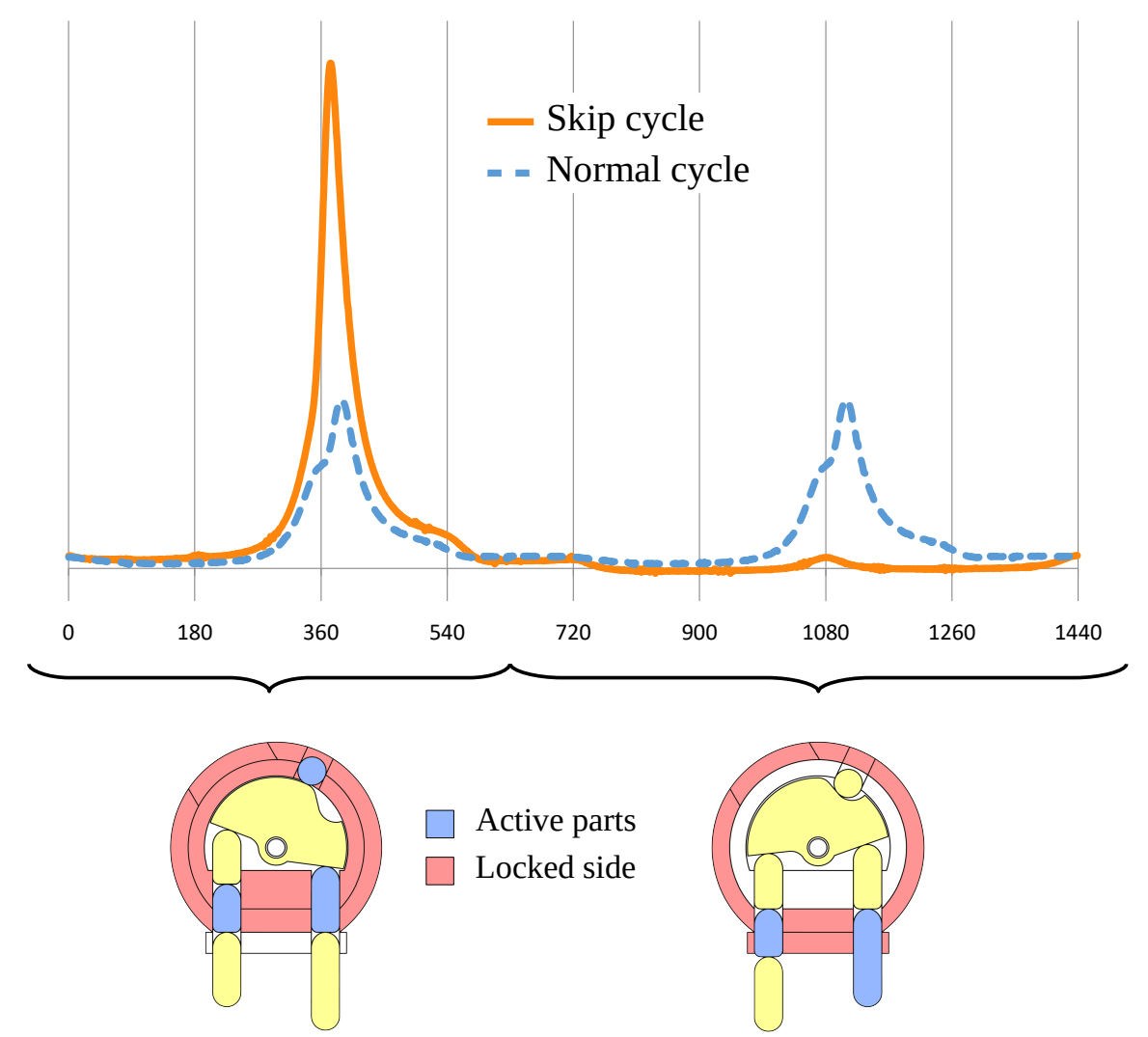

Figure 5: Mechanism positions in Normal and Skip cycle strategies 


\section{Engine Load Analysis}

The valve control mechanism has been designed for a single-cylinder test engine as shown in Fig.6. It has been modified and converted into a gasoline engine, which is used as the test engine. The camshaft of this engine OHV (Over Head Valve): The valve has been mounted on the cylinder head. The valve has been controlled according to the special profiles on the cam shaft which receives movement from the crankshaft. There are three different profiles on the camshaft. One of them controls the intake valve, while the second for the exhaust valve. The middle one controls the diesel pump. This profile will not be used during experiments because the test engine has been converted to a gasoline engine.

The camshaft transmits the circular motion from crankshaft to the valve tappet with the help of the profiles. The push rod is placed at the bottom of the tappet valve with a spherical joint. It is articulated to the adjusting screw at the top and transmits the linear motion to the rocker arm. There must be a gap between cylinders and valves, according to the type and design of the engine. The test engine has a valve clearance of $0,2 \mathrm{~mm}$. This clearance is determined by the position of the adjusting screw. The rocker transmits the movement to the valve by changing the ratio of the distance between the arms. When the valve part is examined, a structure mounted on a prestressed torsion spring is seen. In addition, these springs have a high spring coefficient that allows to contact between tappet valve and cam profile when the mechanism is at high speeds.

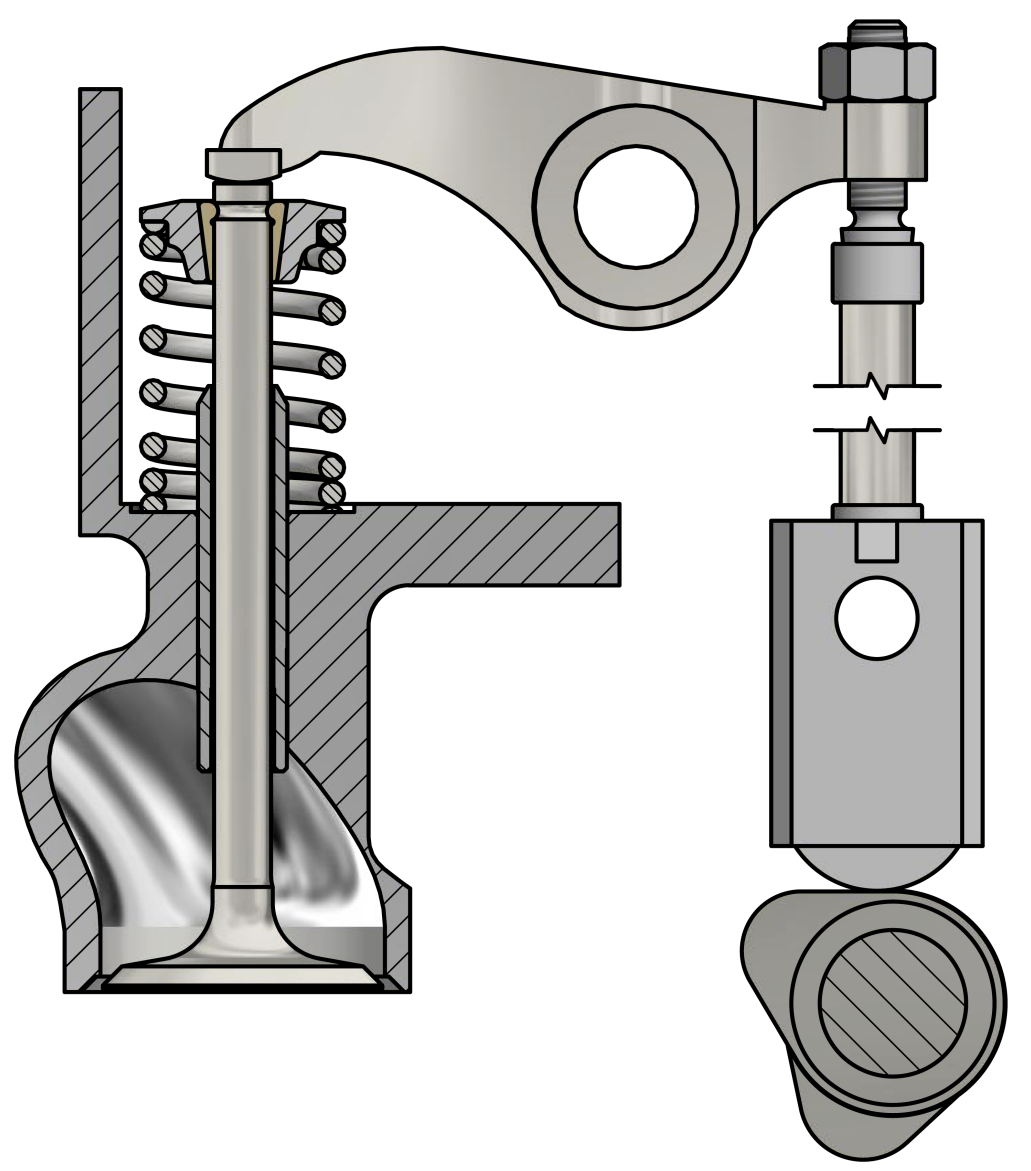

Figure 6: Test engine valve train mechanism

The magnitudes that affect the mechanism design depend on the inertia forces that are directly proportional to the acceleration. Acceleration depends on the cam profile, in other words, it is related to the motion equation of cam. Many curves are used to determine cam profiles. Calculations of harmonic, parabolic and cycloid curves are easy. However, considering the 
information obtained from the technical drawings and the characteristics of the test engine, these curves have been seen inadequate at high speeds. In such cases, advanced curves are used. In this study, "Polidin" curves developed by Dudley (1952) have been used when the characteristics of the test engine were taken into consideration [12]. Differential equations have been used in the solution of motion equations and follower in the polydin curves.

The polynomial curve equation to be used represents only one side (positive angle values) of the cam profile. The negative values of the cam angle $(\theta)$ have to be calculated with reference to the maximum displacement point in order to draw for the symmetrical second side. Solution equation is obtained by using 6 boundary conditions for 3-4-5 polynomial equations. The equation giving the general definition of the polynomial curves is used in order to obtain it $((1))$.

$$
\begin{array}{r}
y=1-10 \theta^{3}+15 \theta^{4}-6 \theta^{5} \\
y^{\prime}=-30 \theta^{2}+60 \theta^{3}-30 \theta^{4} \\
y^{\prime \prime}=-60 \theta+180 \theta^{2}-120 \theta^{3}
\end{array}
$$

It has been determined that the cam lift actuating the intake valve is $6.55 \mathrm{~mm}$. This maximum displacement takes place at an angle of $140^{\circ}$. The cam lobe climbs between $0^{\circ}$ and $70^{\circ}$, while it goes down between the angles of $70^{\circ}-140^{\circ}$. Taking these values into consideration, the equation of motion 3-4-5 is multiplied by the expression $6.55 / 70 n$ to obtain the equation of motion of the intake cam lobe of the test engine. Fig.7.

$$
\begin{aligned}
y=6,55 & -65,5\left[\frac{\theta}{70}\right]^{3}+98,25\left[\frac{\theta}{70}\right]^{4}-39,3\left[\frac{\theta}{70}\right]^{5} \\
y^{\prime} & =-2,8\left[\frac{\theta}{70}\right]^{2}+5,61\left[\frac{\theta}{70}\right]^{3}-2,8\left[\frac{\theta}{70}\right]^{4} \\
y^{\prime \prime} & =-0,08\left[\frac{\theta}{70}\right]+0,24\left[\frac{\theta}{70}\right]^{2}-0,16\left[\frac{\theta}{70}\right]^{3}
\end{aligned}
$$
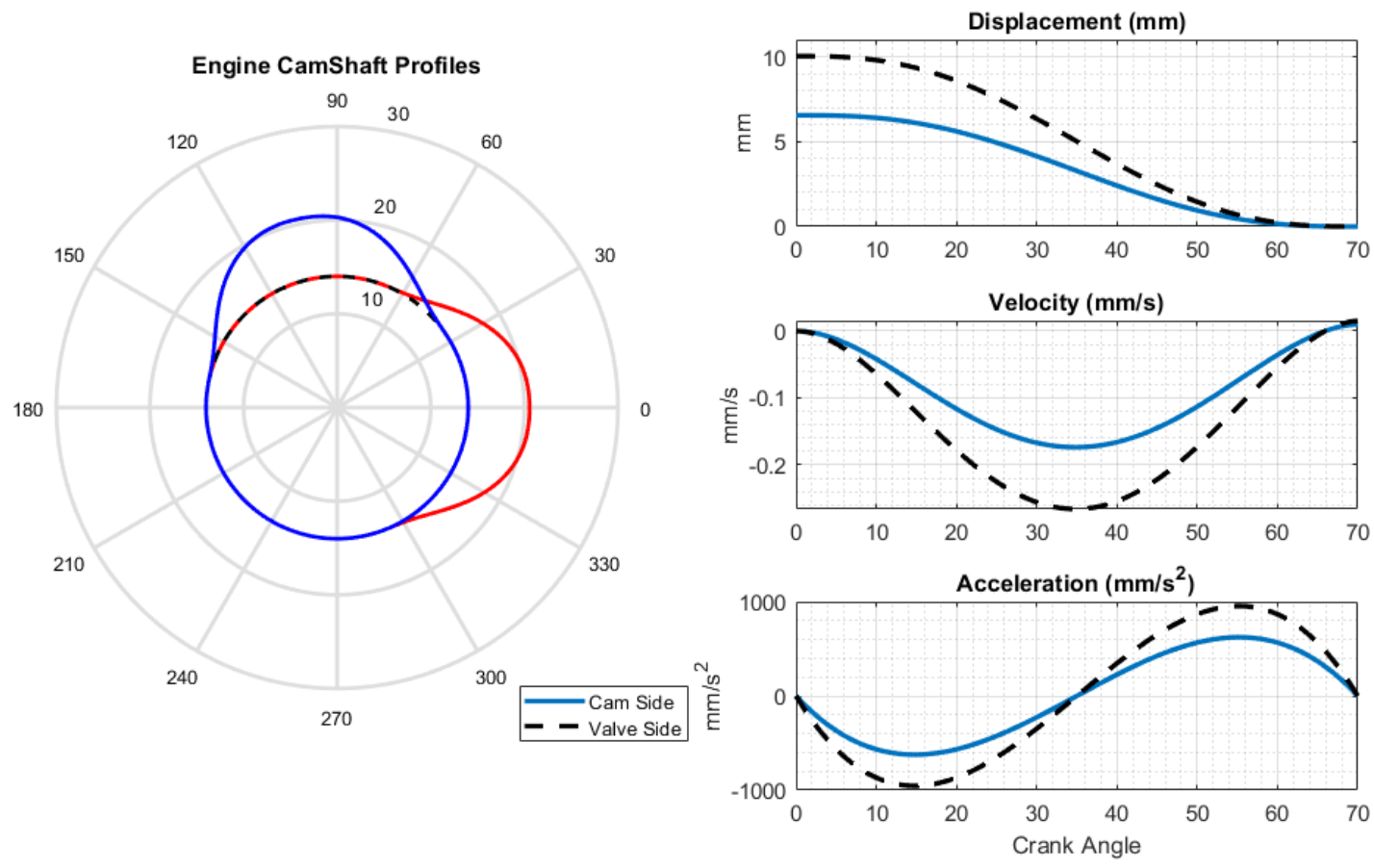

Figure 7: Engine Cam diagrams 
The maximum force is obtained when the valve spring is in its maximum compression state. In force analysis, it is also necessary to include the inertia of the rocker in the system. This inertia will not be equal due to the difference in lift between the two rocker arms. The easiest way to carry out calculations is to determine the valve equivalent mass on the valve side. The system has been considered to be a two-mass model with a suitable size and position. Fig.8.

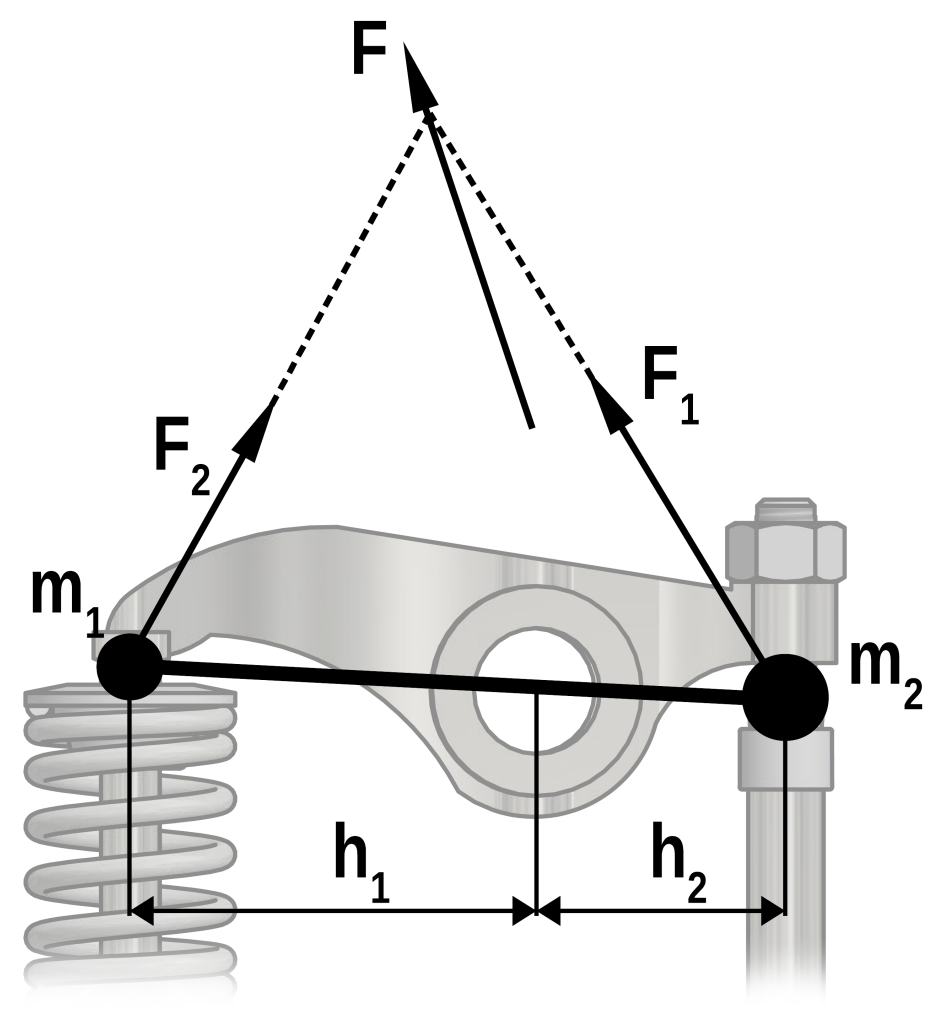

Figure 8: Rocker arm two mass model

The system should produce reaction forces equal to the system forces. In the kinetic equivalent system shown in Fig.8, m represents mass, IG is the moment of inertia with respect to the center of gravity, $m_{1}$ and $m_{2}$ are the mass in two-mass equivalent system, and $h_{1}$ and $h_{2}$ denote the distance from the center of gravity of equivalent masses.

$$
m_{1}+m_{2}=m
$$

$$
m_{1} \cdot h_{1}=m_{2} \cdot h_{2}
$$

$$
m_{1} \cdot h_{1}^{2}+m_{2} \cdot h_{2}^{2}=m \cdot k^{2}
$$

If it is written the equation (4) into the equation (5), it is found

$$
m_{1} \cdot h_{1}^{2}+m_{2} \cdot h_{1} \cdot h_{2}=m \cdot k^{2}=I_{G}
$$

Here, $\mathrm{k}$ is the radius of inertia with respect to the center of gravity . Mass on the cam side,

$$
m_{1}=\frac{m \cdot k^{2}}{h_{1} \cdot\left(h_{1} \cdot h_{2}\right)}
$$


Using equations (3) and (4), the simplest form

$$
m_{1}=\frac{m \cdot h_{2}}{h_{1}+h_{2}}
$$

Inertia radius,

$$
k^{2}=h_{1} \cdot h_{2}
$$

The masses of the system elements have been weighed on the sensitive scale in force analysis (Table 2). Because all the elements in the valve mechanism have linear motion, the masses will be added directly to the force calculation. Since the rocker makes circular motion, the mass will be detected by performing a two-mass reduction. The system has been examined separately on the valve side and on the cam side, due to the size difference between the rocker arms.

\begin{tabular}{cc}
\hline Rocker arm & $95,88 \mathrm{gr}$ \\
\hline Set Screw & $7,25 \mathrm{gr}$ \\
\hline Pusher & $123,47 \mathrm{gr}$ \\
\hline Rod & $45,75 \mathrm{gr}$ \\
\hline Follower & $13,61 \mathrm{gr}$ \\
\hline Valve(i) & $52,26 \mathrm{gr}$ \\
\hline Valve(e) & $45,22 \mathrm{gr}$ \\
\hline Rocker arm Shaft & $68,21 \mathrm{gr}$ \\
\hline Valve Claw & $1,29 \mathrm{gr}$ \\
\hline
\end{tabular}

Table 2: The masses of the system elements

The total mass in the cam side is valve tappet, push rod, setting nut, follower. Using the equation(8), if the mass of the camber on the cam side is reduced, $m_{1}$ is found equation(8) The total mass, along with the mass of the other elements, is found equation(8). The principle of D'Alembert, based on Newton's second principle, has been used in the force analysis. Force magnitudes on the cam side and on the valve side are shown between $0^{\circ}$ and $70^{\circ}$ in Fig.9. As a result of the analytical analysis performed, a maximum force of $154 \mathrm{~N}$ has been determined.

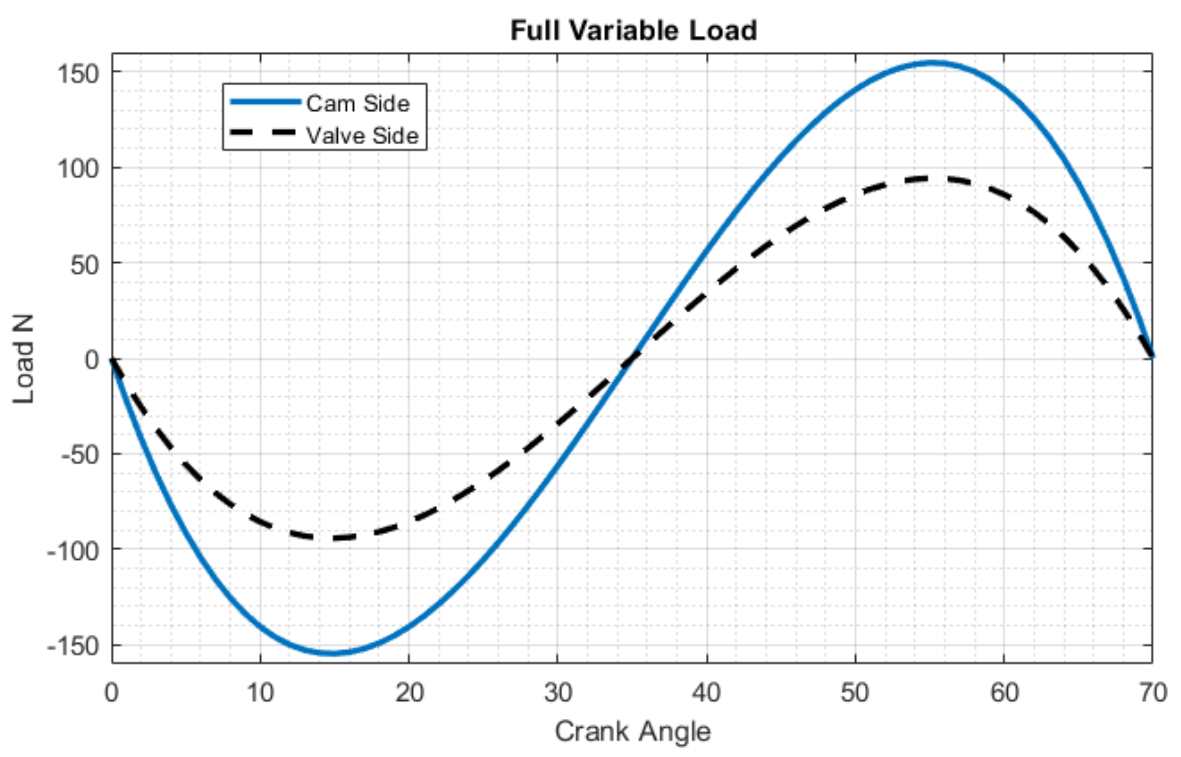

Figure 9: Variable load on valve analytical analysis result 


\subsection{Stress and Fatigue Analyzes}

Skip cycle mechanism performs valve control in two different phases. In the case where the mechanism is active, the normal cycle is carried out, the cycle is skipped when the mechanism is deactivated. The mechanism can be controlled as a normal cycle and skip cycle by means of 5 pin movements in the lock body.

The load affects on the two pins in the skip cycle. In the normal cycle, the load is applied to three points, which are two pins and sphere. The pins have been located in the cylinder head, the spring retainer and the lock body for operation of the system. Therefore, the tolerance and operating conditions of the pins are very important. Looking at the locking pins and the sphere geometry, it can be seen that their sections are circular. There is cutting effect at three different points in locking pin assembly. Since the area under this effect is circular, the maximum stress will be in the neutral axis.

$$
\tau_{\max }=\frac{4}{3} \cdot \frac{F}{A} \cdot \frac{1}{3} \leq \tau_{\text {allow }}
$$

The total force acts as $1 / 3$ of the total load for each pin, since the locking is made (occured) with 3 pins. The pins whose task is controlling and locking in the system have been loaded 50 times in a sec at $1500 \mathrm{~d} / \mathrm{d}$. Therefore, life calculations have been made in addition to the strength calculation of these pins. Fatigue analysis has been performed with a high conversion ratio. If we look at the security factor result in 9 to 1 cycle (Fig.10a), a minimum value is 1,952. This value is above 1 , so it is safe for 9 to 1 cycles. In the next stage, fatigue sensivity graph (Fig.10b) shows the behavior of the load with 50\% load and $400 \%$ load. There is no security problem in life even at $400 \%$ load as shown in graph.
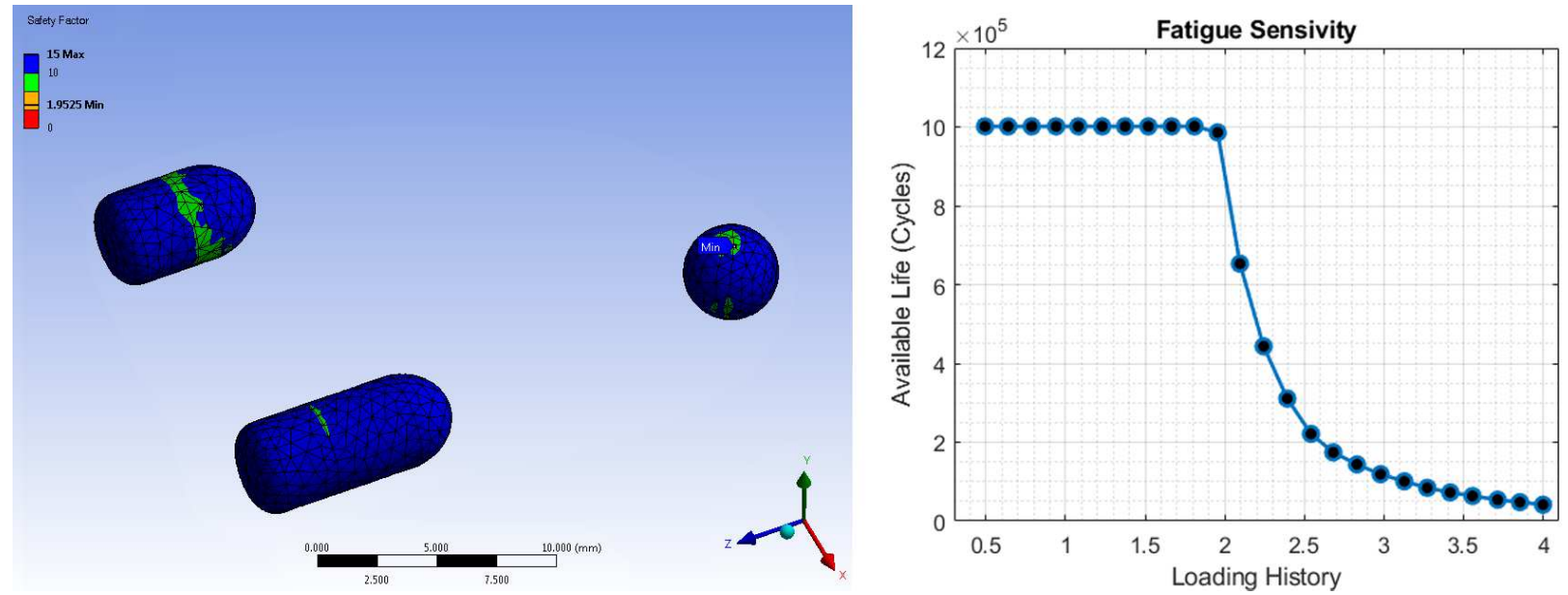

Figure 10: Fatigue analysis results - a) Safety factor, b) Fatigue sensitivity

\section{Experimental Testing of the Skip Cycle Mechanism}

The single-cylinder diesel engine has been chosen as the experimental engine. Because, it has fewer parts and the measurements are suitable for the experiment. Its characteristics are shown in Table 3. Firstly, experiment has been carried out with an electric engine. A $35.5 \mathrm{~mm}$ piece has been added to the cylinder head so that the valve control mechanism could be placed on the system. Thus, it has been adapted to the experimental engine without being interfered with the mounting points. When testing the electric engine, the crankshaft has been manufactured as a flat shaft in order to avoid the balancing problem (Fig. 11). The number of revolutions of the electric motor has been controlled by the motor driver. 


\begin{tabular}{ll}
\hline Number of cylinders & 1 \\
\hline Bore\&Stroke & $85 \mathrm{~mm} \times 80 \mathrm{~mm}$ \\
\hline Compression Ratio & $17,5: 1$ \\
\hline Power & $7 \mathrm{KW} @ 3000 \mathrm{rpm}$ \\
\hline Torque & $28,5 \mathrm{Nm} @ 1700 \mathrm{~d} / \mathrm{d}$ \\
\hline Intake valve dia & $32 \mathrm{~mm}$ \\
\hline Intake valve lift & $10,55 \mathrm{~mm}$ \\
\hline Intake valve opening & $16^{\circ} \mathrm{CA} \mathrm{BTDC}$ \\
\hline Intake valve closing & $40^{\circ} \mathrm{CA}$ ATDC \\
\hline Exhaust Valve dia & $27 \mathrm{~mm}$ \\
\hline Exhaust valve lift & $10,55 \mathrm{~mm}$ \\
\hline Exhaust valve opening & $40^{\circ} \mathrm{CA}$ BBDC \\
\hline Exhaust valve closing & $16^{\circ} \mathrm{CA}$ ATDC \\
\hline
\end{tabular}

Table 3: Test engine specifications
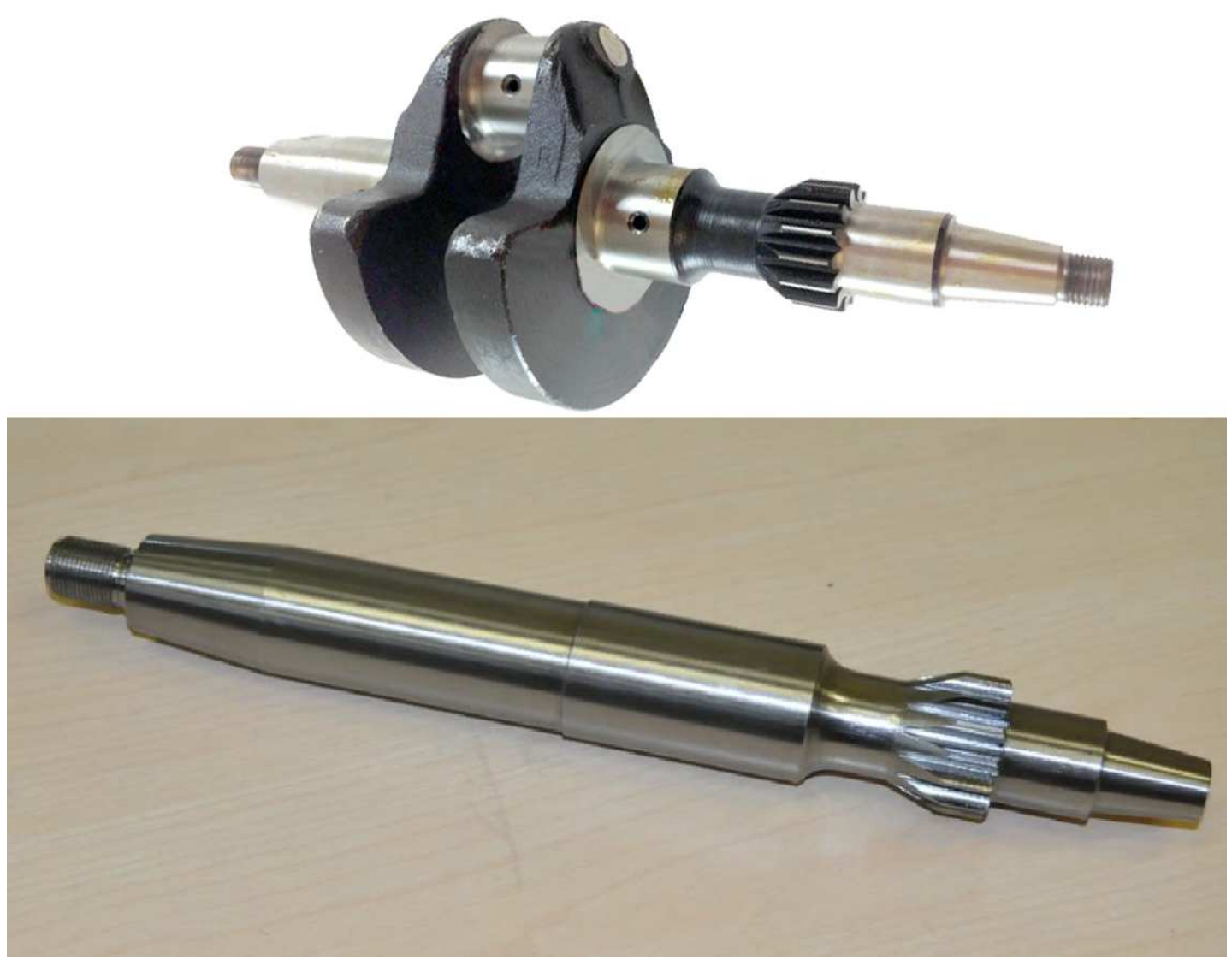

Figure 11: Simplified crankshaft

In the experimental setup, the engine has been driven by an electric motor connected to the $\mathrm{V}$-belt pulley. The AC motor drive has been used to control the number of revolutions of the $\mathrm{AC}$ electric motor and to respond more quickly to possible mechanism lockouts Fig. 12. In addition, the experimental setup has been recorded with a high-speed camera. 


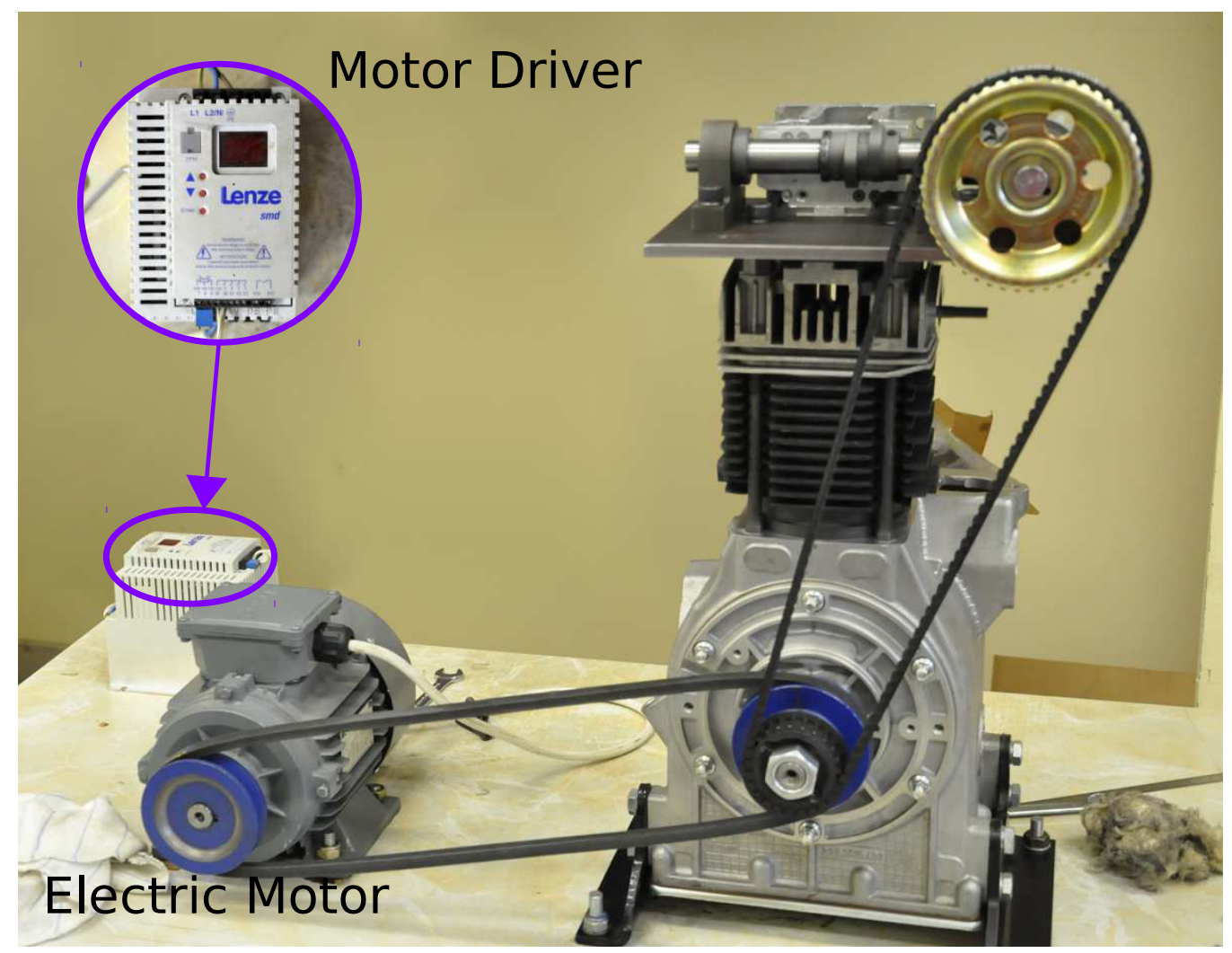

Figure 12: Experiement Set-up

Testing of the mechanism has been carried out in three stages.

1. The pins are at the normal cycle position and can only be operated in normal cycle.

2. The pins are at the skip cycle position and operate in the skip cycle.

3. Testing the system with a cam profile with NS strategy.

In the first step, the timing belt, which provides transmission between the crankshaft and the control camshaft, has been removed and the position of the pins has been adjusted to be the normal cycle. The number of revolutions has been increased from $300 \mathrm{rpm}$ to $1200 \mathrm{rpm}$ with the aid of the potentiometer on the AC motor drive, and the mechanism has been tested (Figure 13). The first stage test has been completed in about 15 minutes with parts control. In the second stage, the position of the pins is in the skip cycle position. The number of revolutions has been increased from $300 \mathrm{rpm}$ to $1200 \mathrm{rpm}$ with the aid of the potentiometer on the AC motor drive, and the mechanism has been tested (Figure 14). Mechanism elements deformation has been checked, as a result of these two tests. 


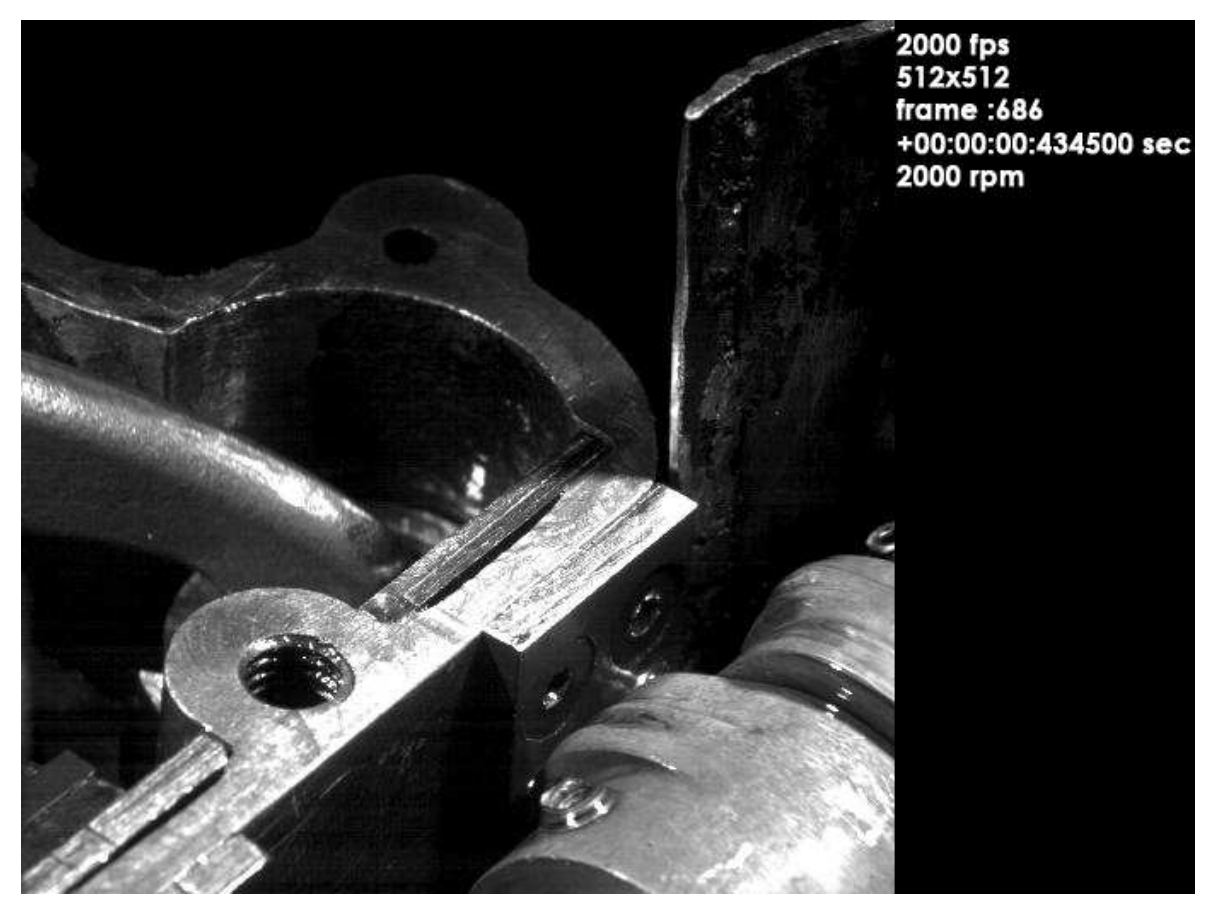

Figure 13: Normal Cycle Mode experiment

At the last stage, the connection between the crankshaft and the control camshaft has been provided by a timing belt. Thus, crankshaft synchronization has been done. The position adjustments have been made by adjusting bolts on the cam profiles in order to adjust the initial control of the mechanism. Initially it has been run at $300 \mathrm{rpm}$ for about 30 seconds. The speed has been gradually increased to $300 \mathrm{rpm}, 500 \mathrm{rpm}, 800 \mathrm{rpm}$ and $1200 \mathrm{rpm}$.

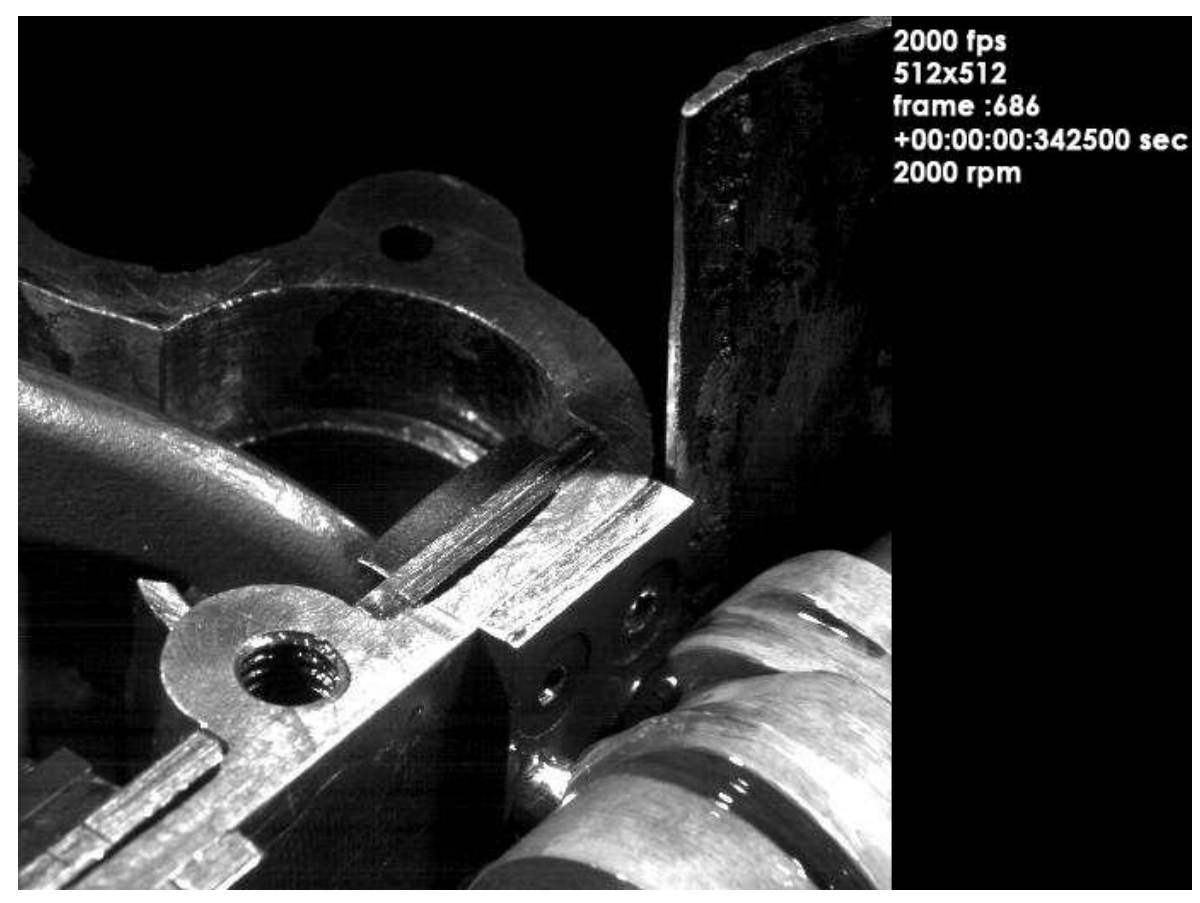

Figure 14: Skip Cycle Mode experiment 


\section{Conclusions}

In this work, the valve locking mechanism has been designed and prototyped for the skip cycle mechanism introduced in 1999 by Kutlar. The design of the mechanism consists of two main parts (the locking mechanism and the control mechanism), which is very important in terms of the suitability of Kutlar to different strategies (NS, NSS, NNS etc.) In addition, filler leaks have been prevented by mechanical locking. The experimental engine has been solved kinematically and the data obtained from this analysis has been used in mechanism design. Alternative changes on the design can be seen quickly in the analyzes because all designs are created in 3D. Dynamic simulations have been performed with real parameters and the problems of the systems obtained from these simulations have been determined so that appropriate solutions for these problems have been tried to be found in the new design. It has been determined that the materials of the mechanism parts are appropriate as a result of static and fatigue analyzes.] The system is flexible because the mechanism has been designed to fit many different strategies. An experimental setup has been established in Istanbul Technical University Automotive Laboratory, and the assembly has been completed and experiments have been carried out. It has been determined that the mechanism works smoothly as a result of the experiments. In addition, the test engine has been connected to the electromagnetic brake; therefore, fuel consumption values have been obtained when only the intake valve is controlled.

First prototype engine was equipped with an additional rotary valve at intake channel driven by a rotary solenoid. During skipping cycle, rotary valve is closed, fuel injection and ignition is cut off. There was not any intervention to control the inlet and exhaust poppet valves. Experimental results on engine dynamometer shows that rotary valve in intake channel could not hold back completely the flow into the combustion chamber. This results with a loss of fresh charge during skipping cycle, consequently increasing $\mathrm{HC}$ emissions and fuel consumption. It was only possible at very low loads and in NSS working condition to reduce the fuel consumption.

Second prototype engine was equipped with a mechanism, which allows pushing and pulling back the eccentric shaft hence via disconnecting the cam fallower, deactivating the inlet and exhaust valves during skipping cycle. If the mechanism is mounted the engine runs only with one skip cycle (NS) without the ability to changing the working cycles like normal four stroke or two skipping cycle (NSS). Experimental results on engine dynamometer shows that the mechanism could stop fully the charge exchange between combustion chamber and inlet- exhaust-channels during skipping cycle. With one skip cycle (NS) it was possible to reduce the fuel consumption and pumping losses during gas exchange, in comparison to normal four stroke working conditions at low load regimes. At load conditions between 1-3 bar brake mean effective pressure (BMEPpme) fuel consumption reduction was between 14-26\%. Table 4. Figure 15) 


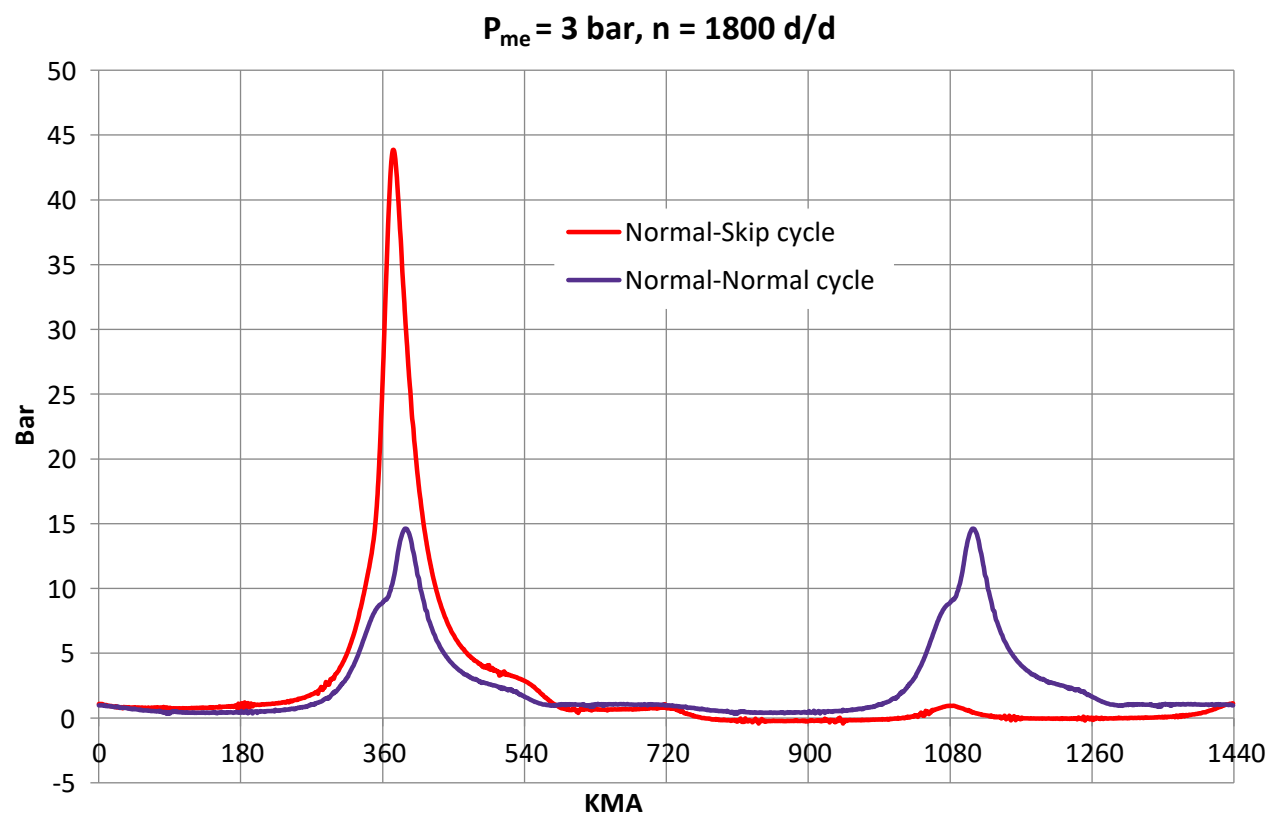

Figure 15: Experiment Results

The subject of this article is to develop a mechanism, which allows the transition between working modes. Mentioned working modes may be normal four-stroke cycle, one normal and one skipping cycle (NS), one normal and two skipping cycle (NSS) etc. which can be expanded depending on load condition, applied strategy and design of mechanism.[13]

\begin{tabular}{cccccccccc}
\hline & \multicolumn{3}{c}{$p_{m e}=1$ bar } & \multicolumn{3}{c}{$p_{m e}=2$ bar } & \multicolumn{3}{c}{$p_{m e}=3$ bar } \\
\hline $\mathbf{n ~ ( d / d )}$ & N & NS & Diff. \% & N & NS & Diff. \% & N & NS & Diff. \% \\
\hline 1200 & 1055 & 780 & -26 & 587 & 485 & -17 & 491 & 404 & -18 \\
\hline 1350 & 927 & 731 & -21 & 565 & 483 & -14 & 484 & 400 & -17 \\
\hline 1500 & 913 & 722 & -21 & 564 & 478 & -15 & 477 & 396 & -17 \\
\hline 1650 & 905 & 695 & -23 & 561 & 475 & -15 & 475 & 398 & -16 \\
\hline 1800 & 939 & 777 & -17 & 581 & 486 & -16 & 477 & 395 & -17 \\
\hline
\end{tabular}

Table 4: Experimental results 


\section{Declarations}

Availability of data and materials : The authors confirm that the data supporting the findings of this study are available within the article [and/or] its supplementary materials.

Competing interests : Not applicable

Funding : Not applicable

Authors' contributions

Firat Mehmet Günkan: Conceptualization, Methodology, Software, Data curation, WritingOriginal draft preparation,

Cemal Baykara: Conceptualization, Supervision, Writing- Reviewing and Editing, Validation

Osman Akin Kutlar: Conceptualization, Validation

Acknowledgements: Not applicable 


\section{References}

[1] Adam T.J.M. Rose, Sam Akehurst, and Chris J. Brace. Investigation into the tradeoff between the part-load fuel efficiency and the transient response for a highly boosted downsized gasoline engine with a supercharger driven through a continuously variable transmission. Proceedings of the Institution of Mechanical Engineers, Part D: Journal of Automobile Engineering, 227(12):1674-1686, 2013.

[2] A. Javaheri, V. Esfahanian, A. Salavati-Zadeh, and M. Darzi. Energetic and exergetic analyses of a variable compression ratio spark ignition gas engine. Energy Conversion and Management, 88:739-748, 2014.

[3] Alper Tolga Calik Osman Akin Kutlar, Hikmet Arslan. Methods to improve efficiency of four stroke, spark ignition engines at part load. Energy Conversion and Management, 46:3202-3220, 2005.

[4] Saeed A. Albatlan and Eid S. Mohamed. Dynamic analysis and experimental evaluation of variable valve lift system for internal combustion engine with double overhead camshaft. International Journal of Vehicle Structures and Systems, 6(1-2):24-31, 2014.

[5] Christoph Luttermann, Erik Schueenemann, and Norbert. Klauer. Enhanced VALVETRONIC technology for meeting SULEV emission requirements. Society of Automotive Engineers, [Special Publication] SP, SP-2025(Advanced Catalysts and Substrates 2006):7$11,2006$.

[6] Robert Huber, Peter Klumpp, and Heinz Ulbrich. Dynamic Analysis of the Audi Valvelift System. SAE International Journal of Engines, 3(1):2010-01-1195, 2010.

[7] Claus Brüstle and Dietmar Schwarzenthal. VarioCam Plus - A Highlight of the Porsche 911 Turbo Engine. SAE Technical Paper, 2001(724), 2001.

[8] Kosuke Nagaya, Hiroyuki Kobayashi, and Kazuya Koike. Valve timing and valve lift control mechanism for engines. Mechatronics, 16(2):121-129, 2006.

[9] Eaton Corporation Beachwood. Variable valve actuation rocker arm assembly, 2014.

[10] Yasuyuki Morita. Engine Valve Mechanism Having Valve Disabling Device. 1984.

[11] Richard van Basshuysen. Cylinder deactivation and fading out of individual cycles to the fuel economy and exhaust emissions, 1993.

[12] W.M. Dudley. A New Approach to Cam Design. Machine Design, 184, 1952.

[13] Cemal Baykara, O. Akin Kutlar, Baris Dogru, and Hikmet Arslan. Skip cycle method with a valve-control mechanism for spark ignition engines. Energy Conversion and Management, 146(March 2018):134-146, 2017. 
Figures

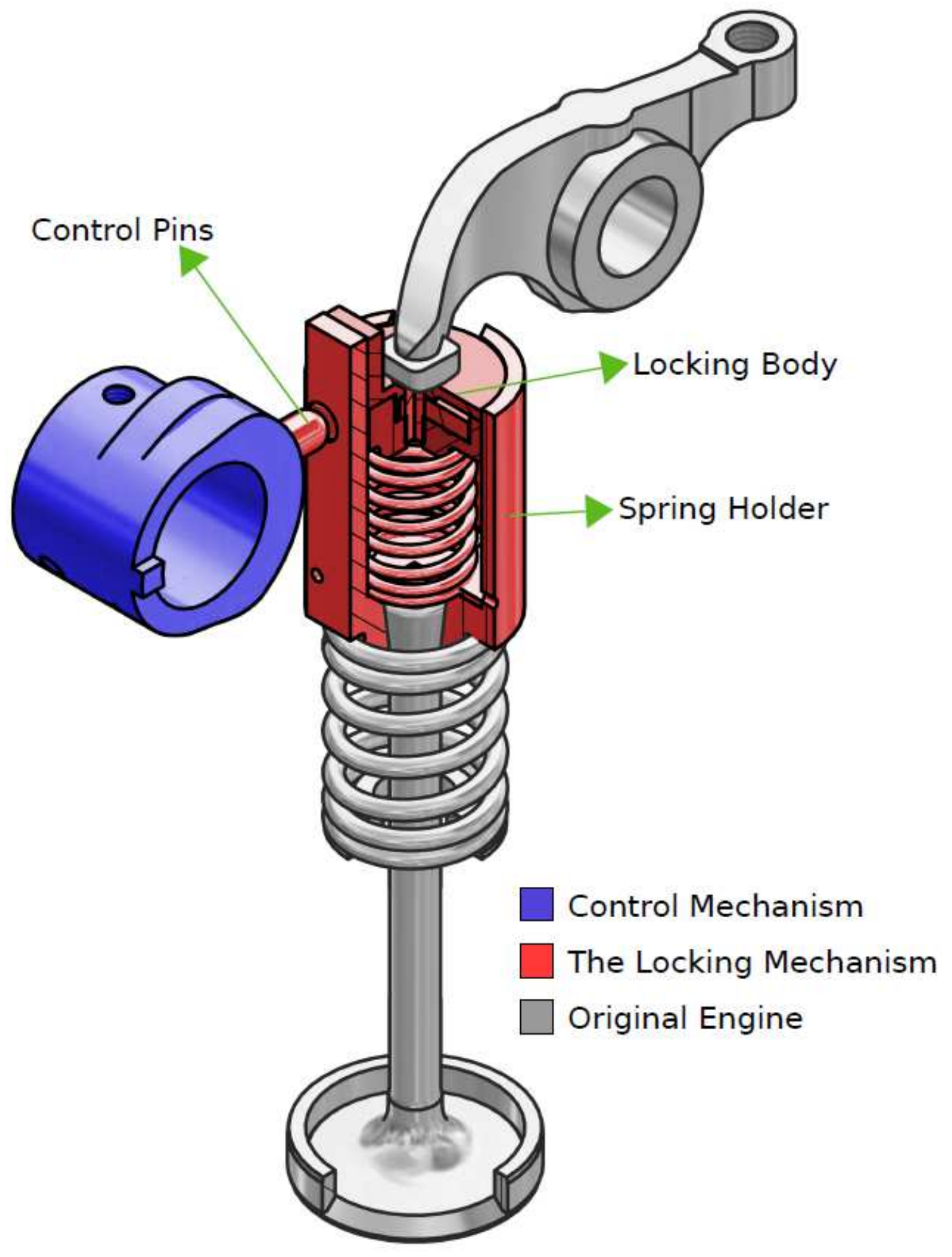

Figure 1

Skip Cycle Mechanism 


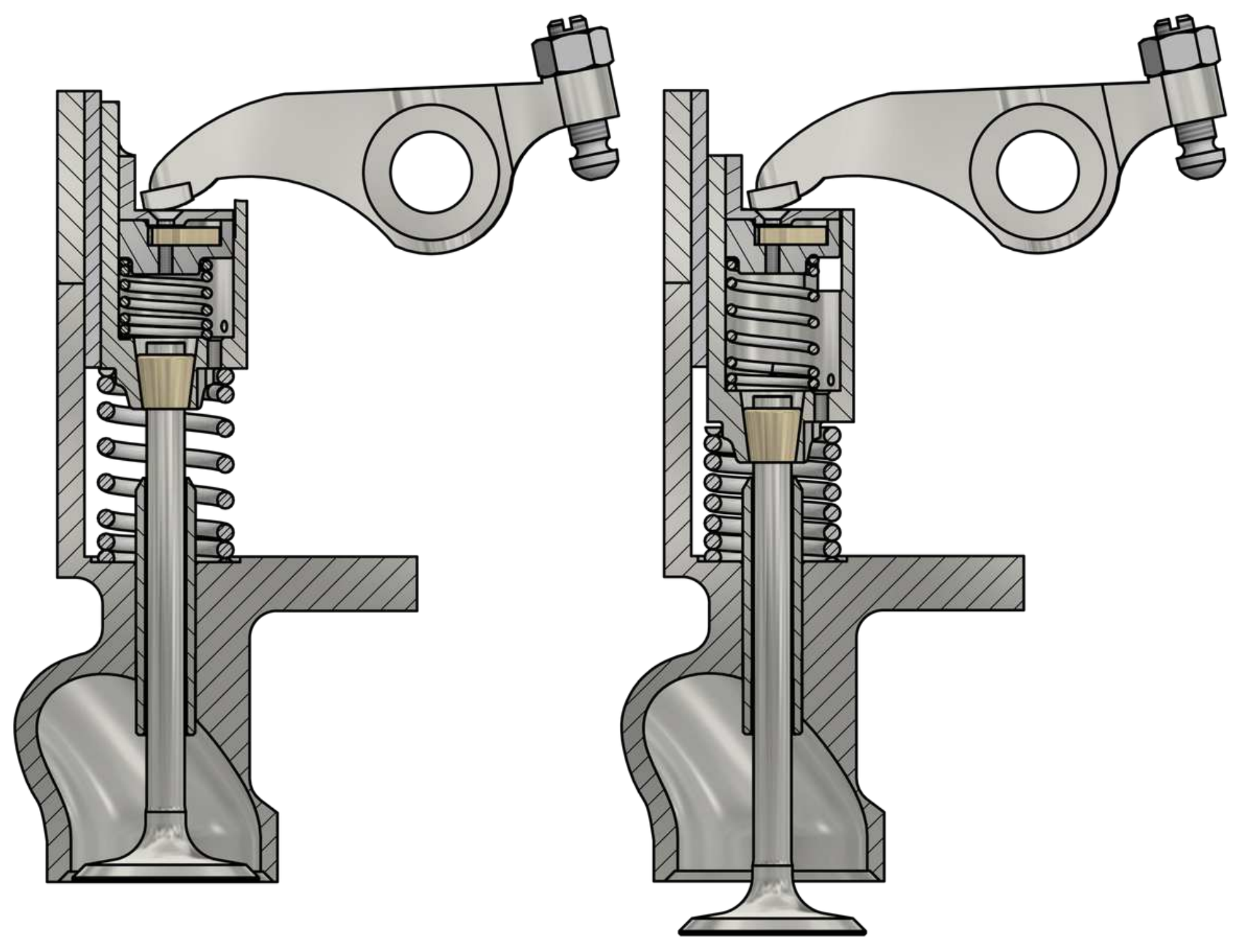

Figure 2

a) Disabled mode (on left), b) Enabled mode (on right) 

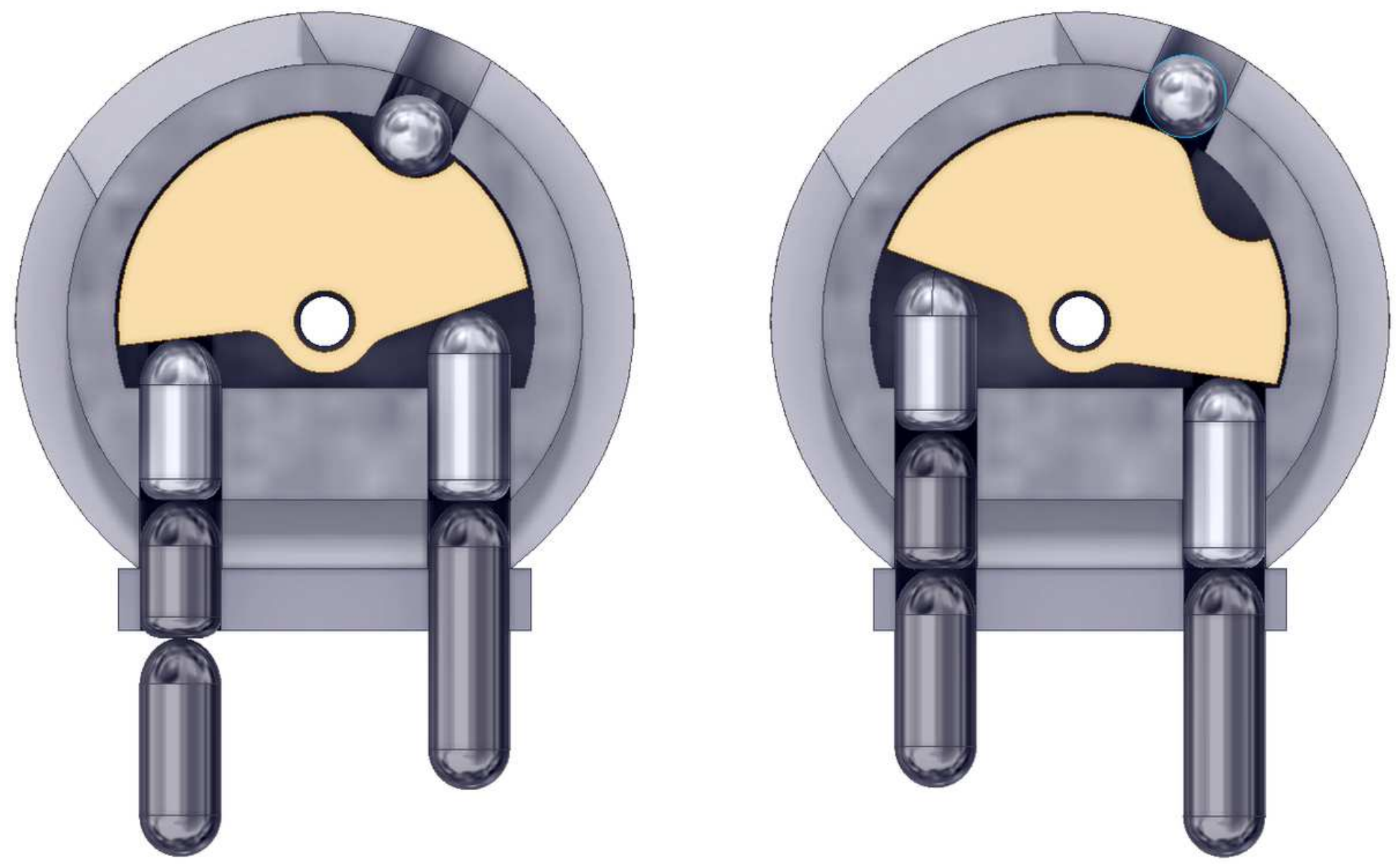

Figure 3

a) Locking position (Skip Cycle), b) Unlocking position (Normal Cycle) 

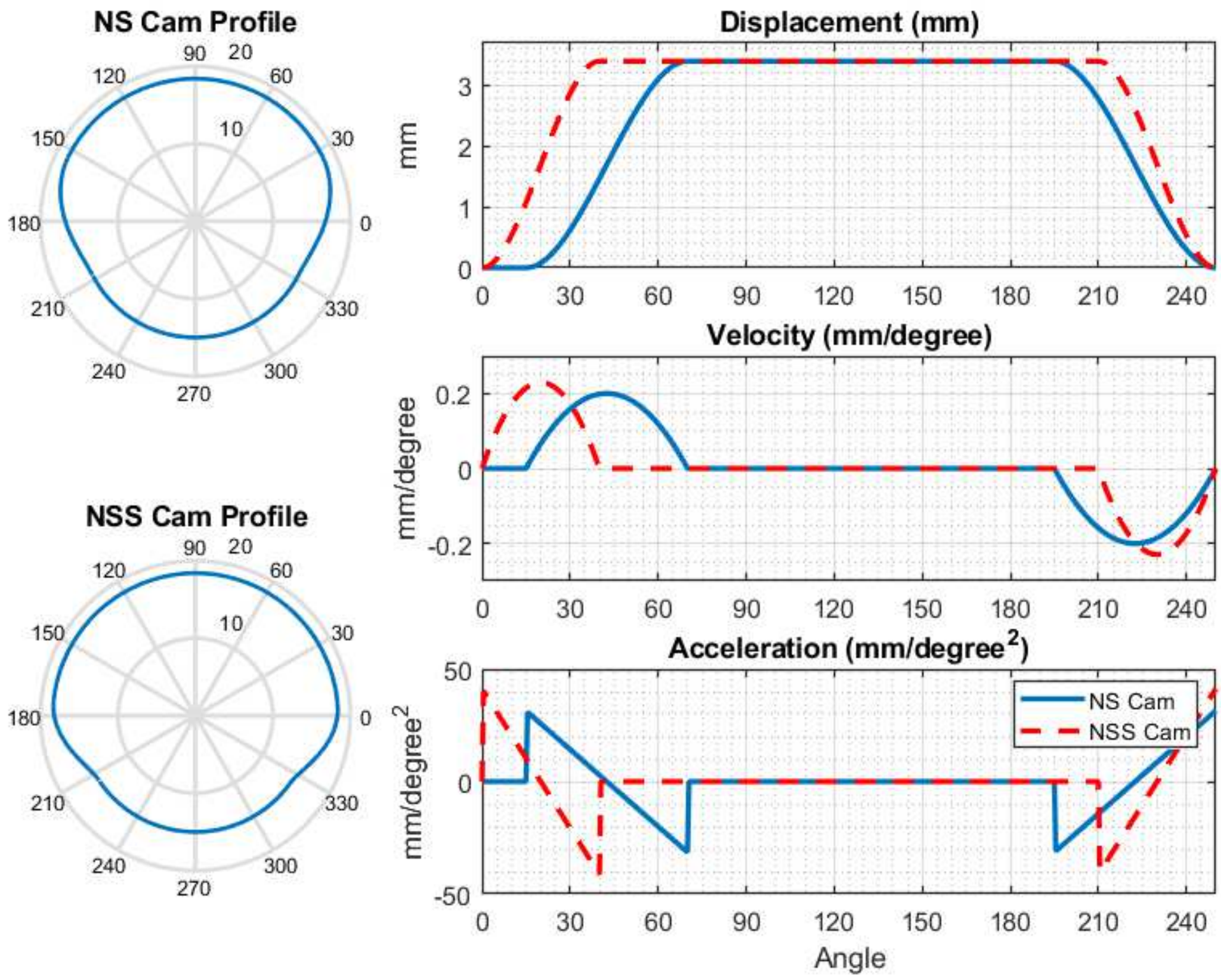

Figure 4

NS and NSS Strategy Control Cam Profiles 


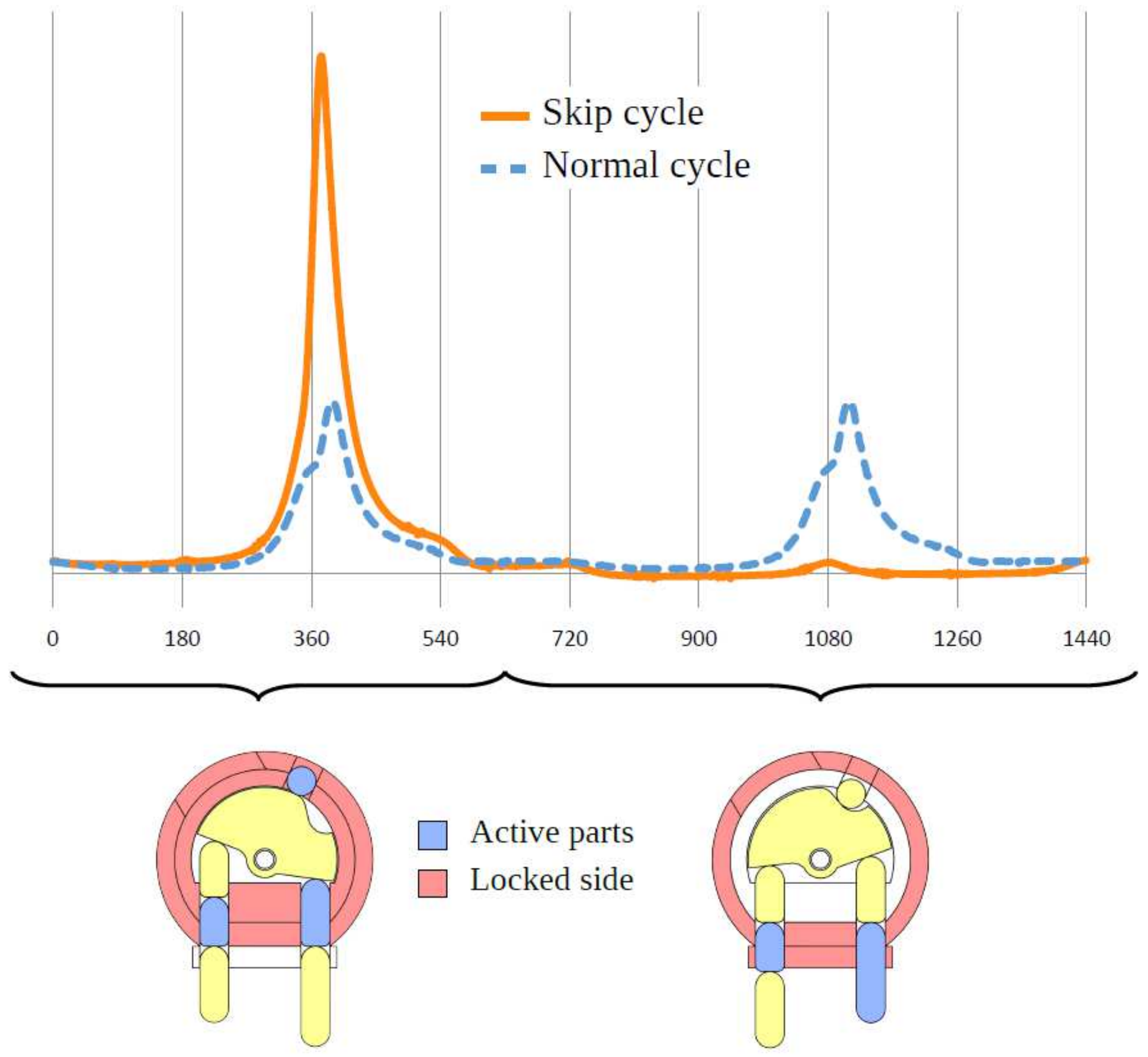

Figure 5

Mechanism positions in Normal and Skip cycle strategies 


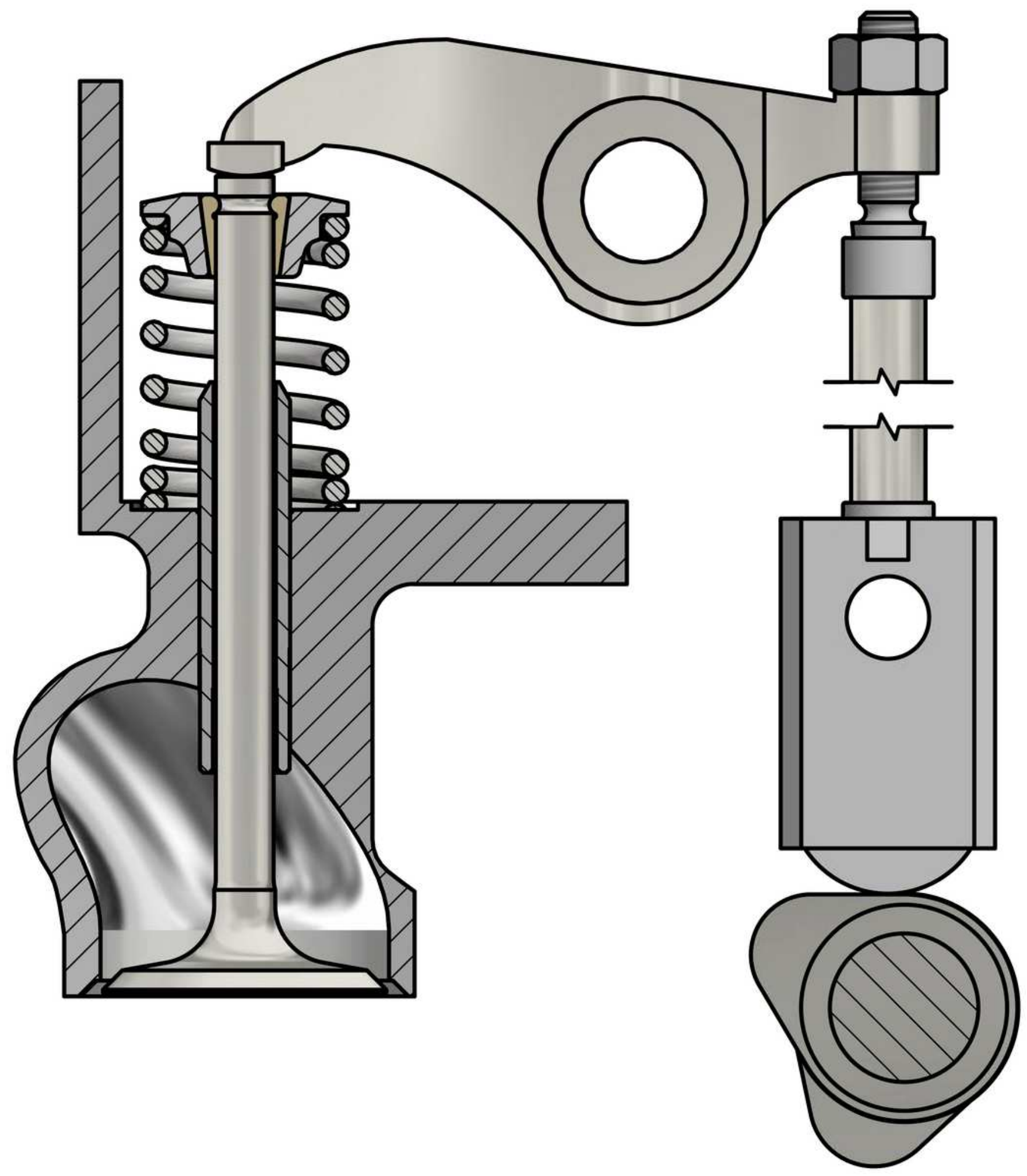

Figure 6

Test engine valve train mechanism 

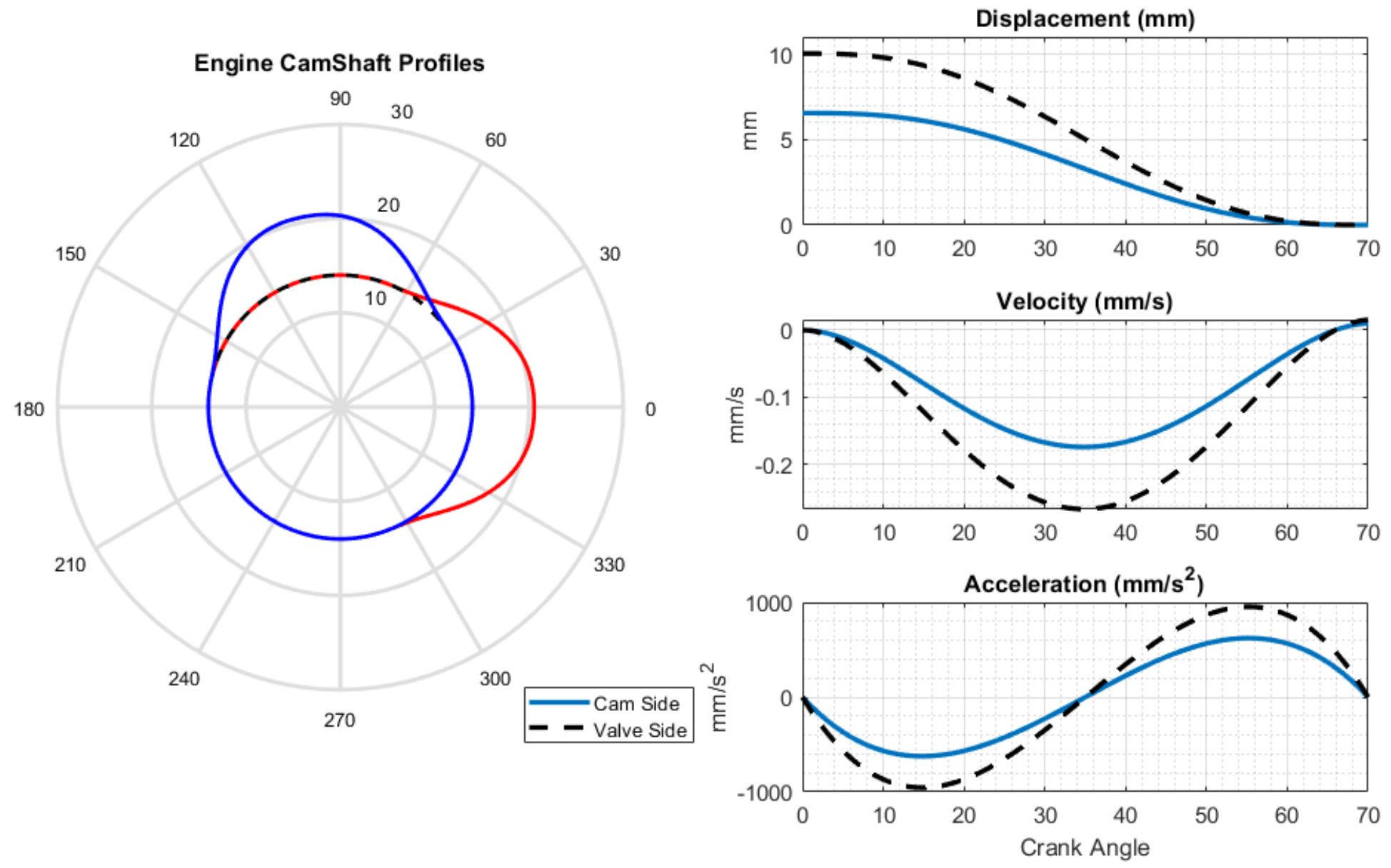

Figure 7

Engine Cam diagrams 


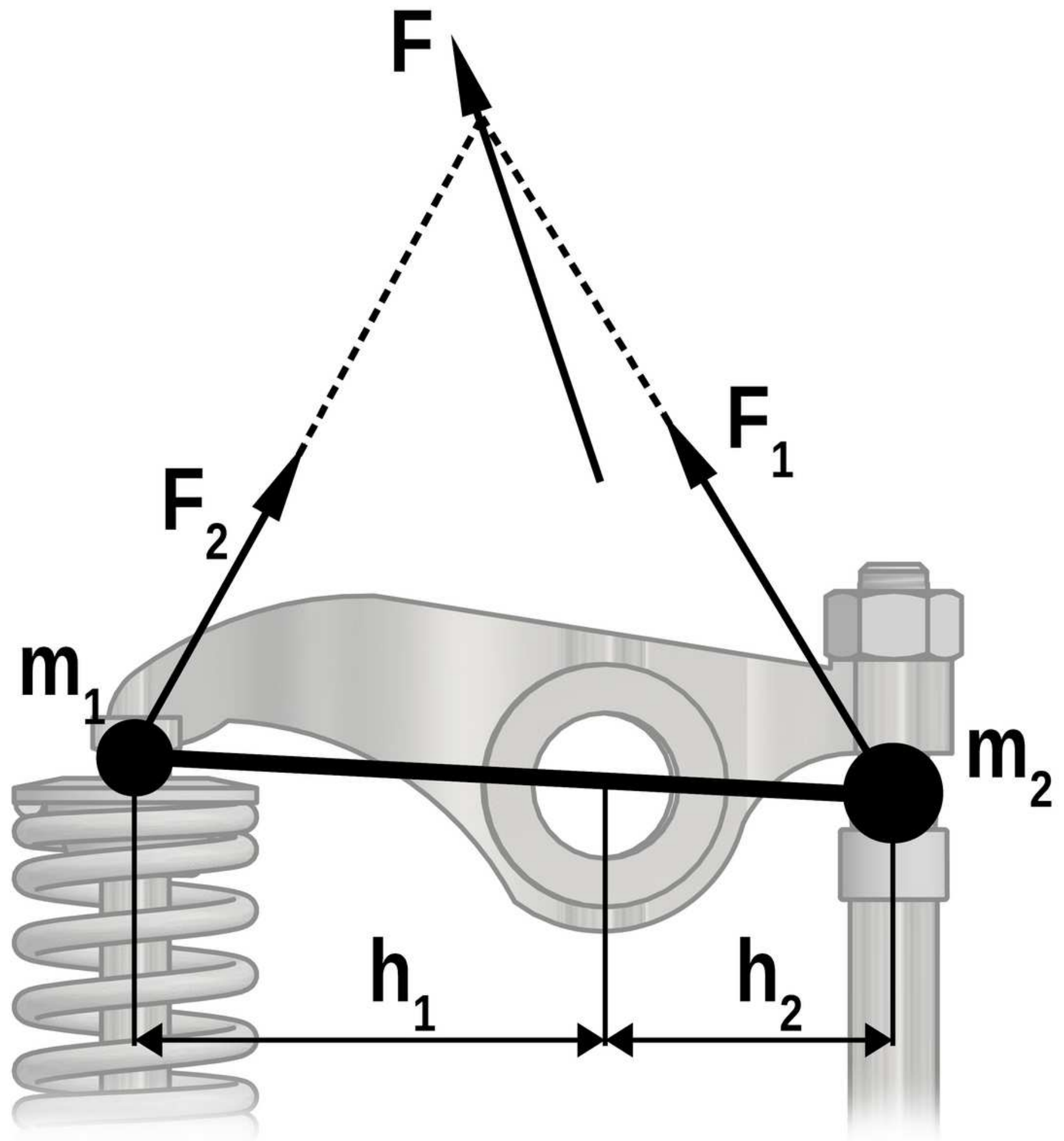

Figure 8

Rocker arm two mass model 


\section{Full Variable Load}

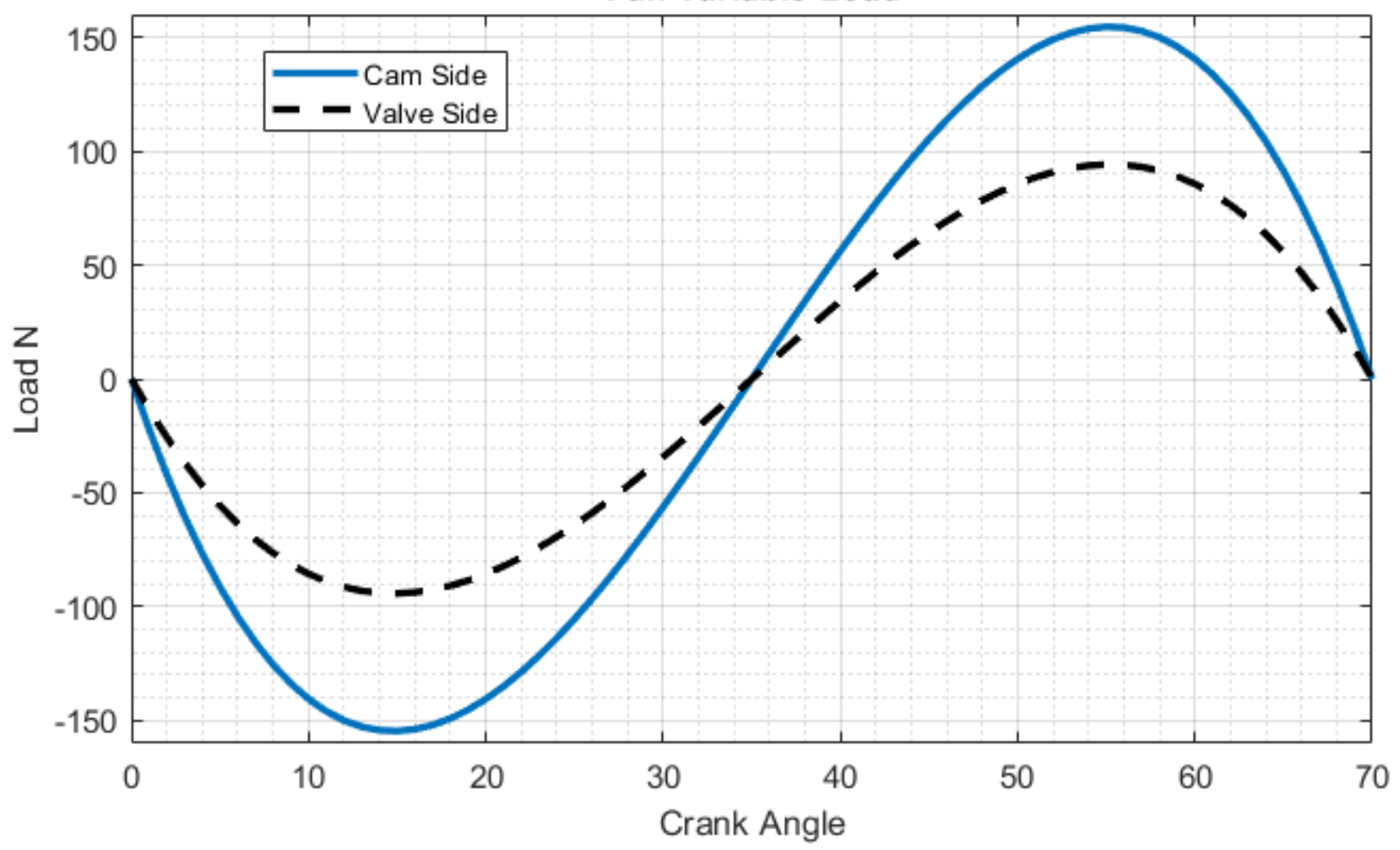

Figure 9

Variable load on valve analytical analysis result
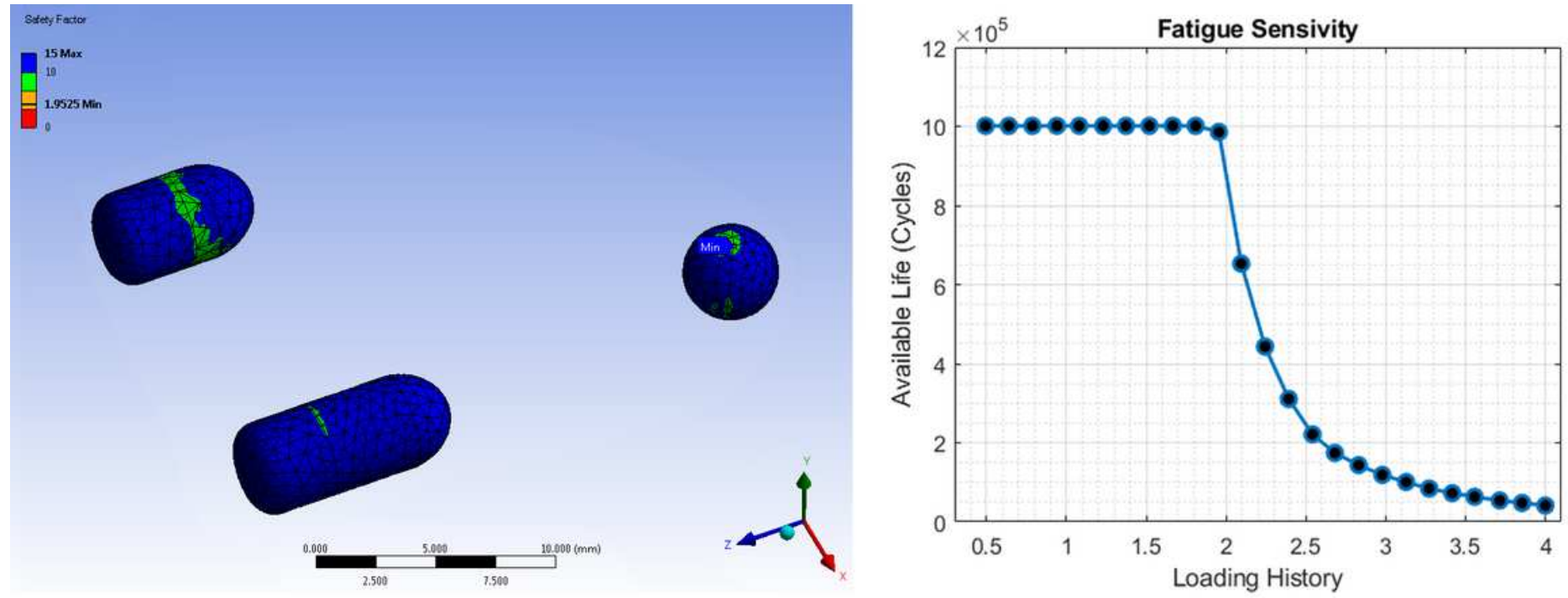

Figure 10

Fatigue analysis results - a) Safety factor, b) Fatigue sensitivity 

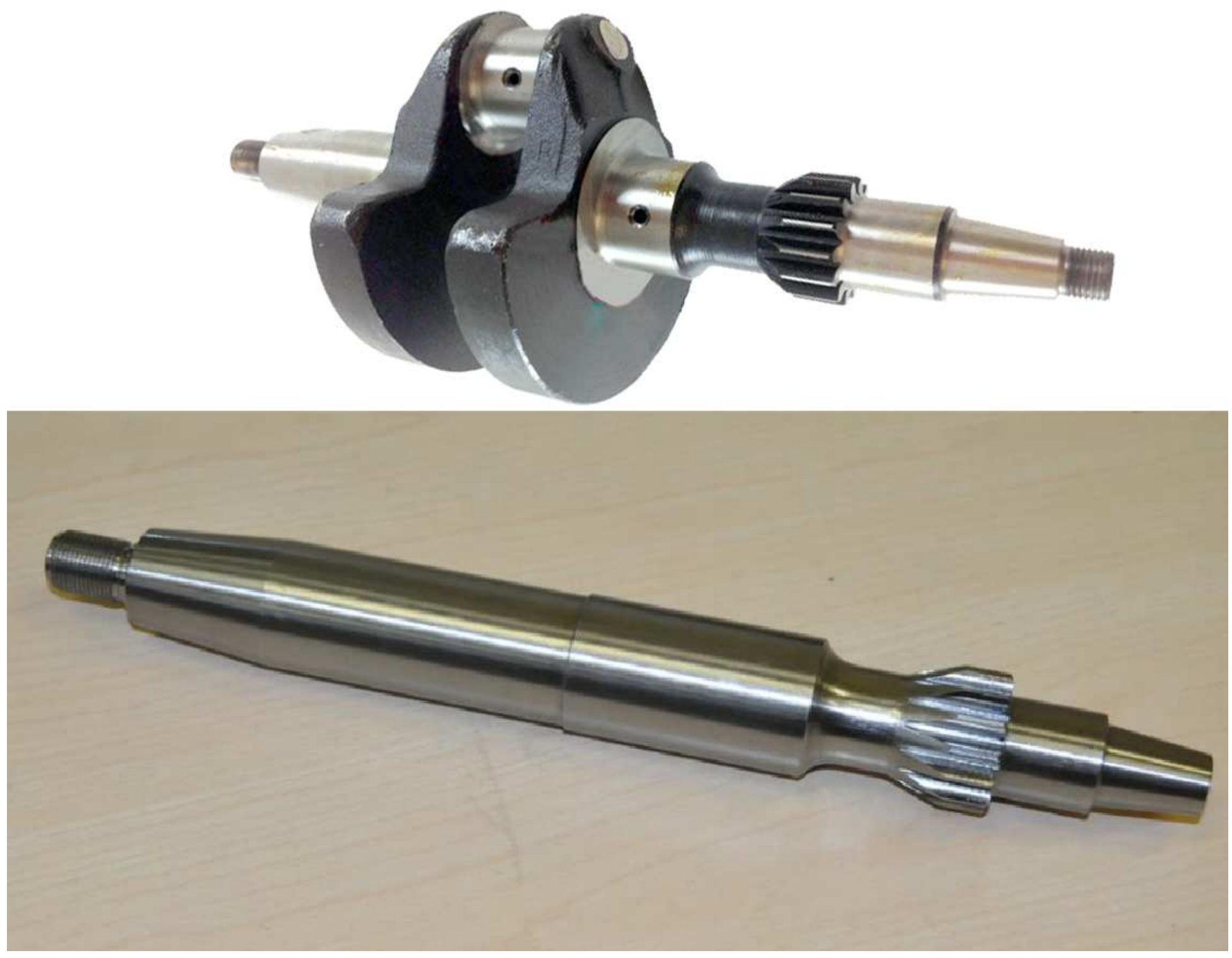

Figure 11

Simplified crankshaft

展

Figure 12

Experiement Set-up 


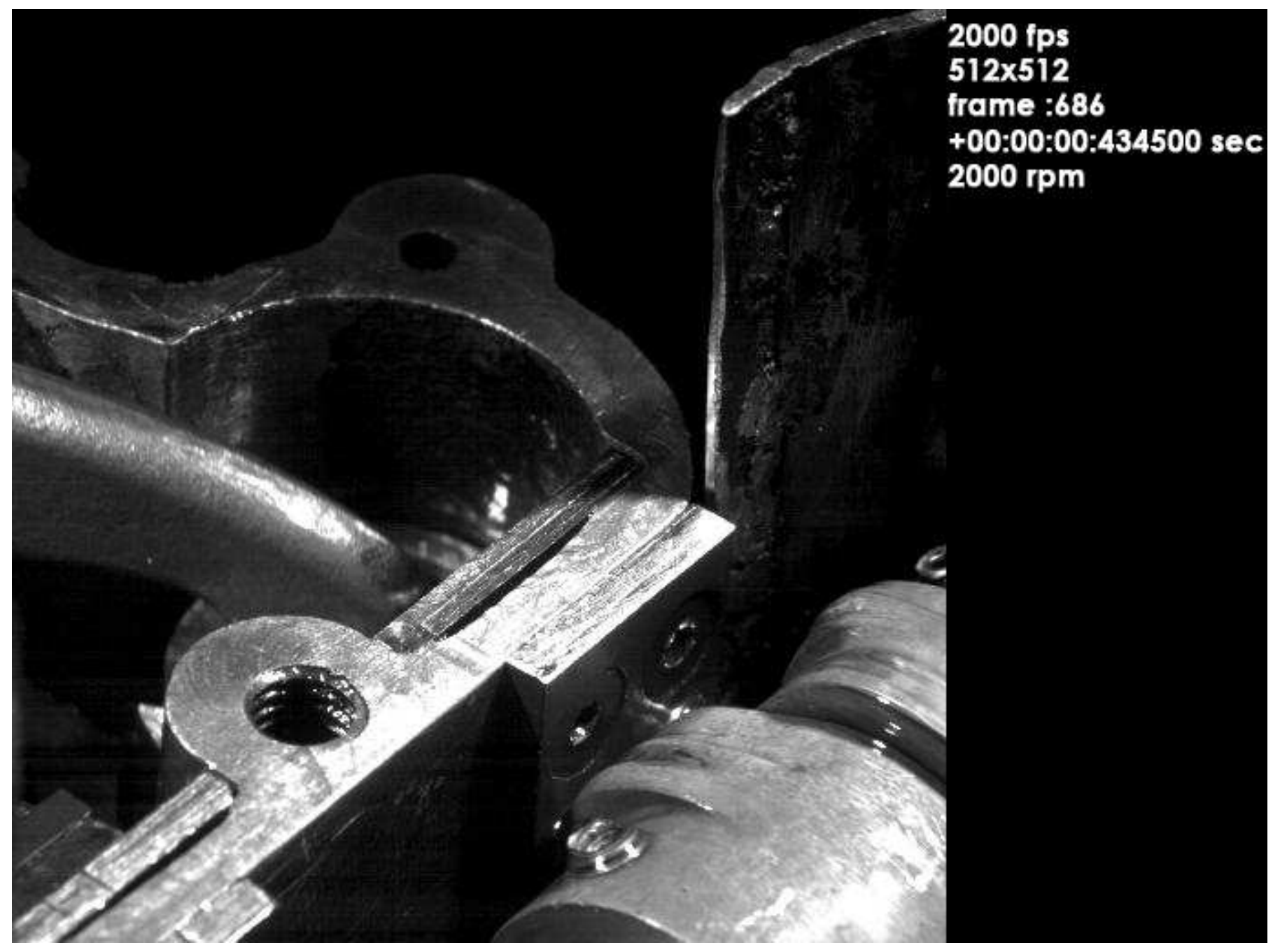

Figure 13

Normal Cycle Mode experiment 


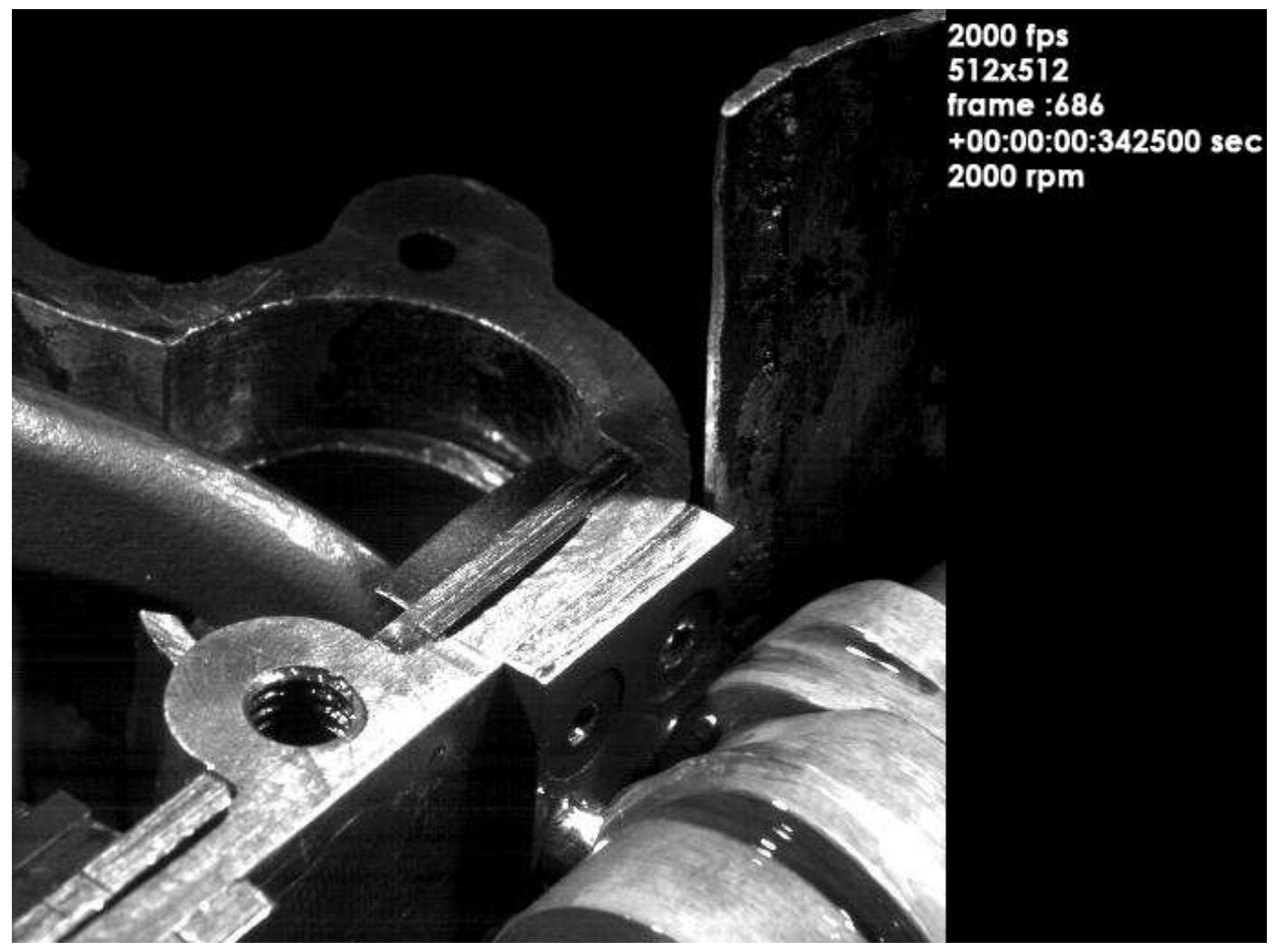

Figure 14

Skip Cycle Mode experiment 


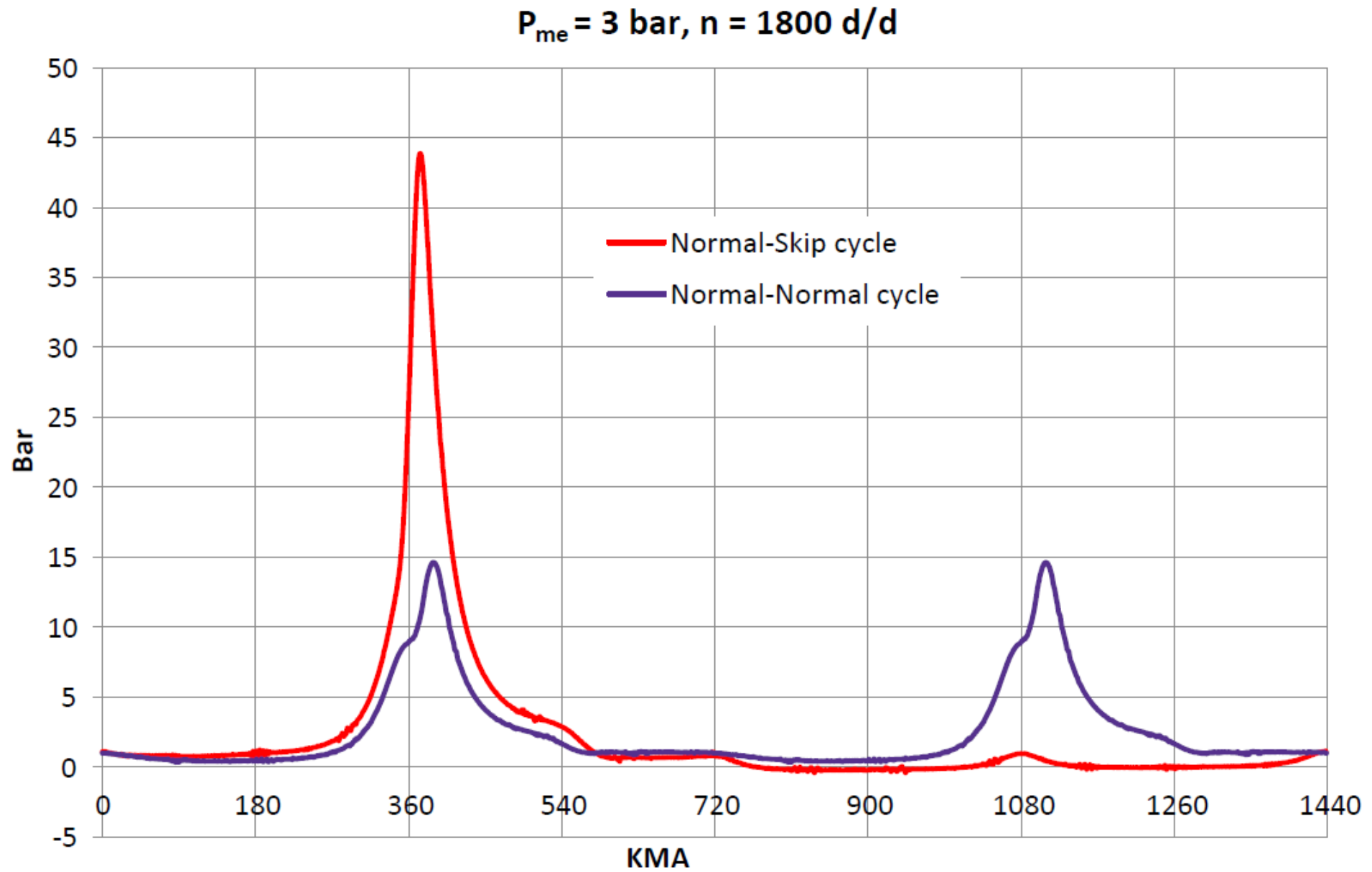

Figure 15

Experiment Results 